\title{
LASER INDUCED BREAKDOWN SPECTROSCOPY (LIBS) APPLIED TO THE QUANTIFICATION OF ELEMENTS IN FERTILIZERS
}

Dissertation presented to the Instituto de Química de São Carlos of the University of São Paulo as part of the requirements for obtaining the title of Masters in Science.

Area of concentration: Analytical and Inorganic Chemistry

Supervisor: Dra. Débora Marcondes Bastos Pereira Milori

São Carlos 


\section{Acknowledgments}

I would like to first thank the University of São Paulo (USP), for the opportunity in letting me become a part of its institution. Completing a Masters program at USP was more than just an academic experience; it was a life changing experience. I was born in the United States of America and before USP, I had never done an academic program abroad, but after my experience at USP I realized how important cultural exchanges are in addition to academic exchanges. As part of the Masters program in chemistry at the Instituto de Química de São Carlos (IQSC) I received not only an academic education, but a valuable life education that touched on various aspects of my life; I gained so much as part of the USP community that it exceeded my expectations and I am thankful to USP for allowing me to do that.

I also want to thank Dr. Emmanuel Carrilho from the Chemistry Department, this professor was helpful and supportive of my decision to attend USP since day 1, I can honestly say that without him, I would have never had the courage to leave my country for so long and come to Brazil. Dr. Carrilho made me feel a sense of comfort and with him by my side I rarely dealt with the difficult transitions that sometimes arise with moving to another country. Everything I learned about myself or through the academic education I attained can be partly due to him because none of it would have happened without him and I am not sure he realizes how much of a positive impact his support had on me.

Lastly, I want to thank Embrapa and my supervisor Dr. Débora Milori for the opportunity in letting me do my research project at the institution in São Carlos, São Paulo (Embrapa Instrumentaçao). While at Embrapa I was able to academically evolve and attain a great amount of knowledge. I was fortunate to be part of a large research group that mainly consisted of people who were higher than me in academic level, which allowed me to learn from them and their academic experiences. 


\begin{abstract}
The ability of the instrument Laser Induced Breakdown Spectroscopy (LIBS) was investigated for the possibility of acting as a quantification tool of analysis. A low-cost gated charged coupled device (CCD) was used to quantify Potassium (K), Calcium (Ca), Manganese $(\mathrm{Mn})$, Magnesium $(\mathrm{Mg})$, and Copper $(\mathrm{Cu})$ present in 26 fertilizer samples made up of different matrices, some of organic-mineral phosphate and others of inorganic material; evaluation of elements in organomineral fertilizers had never been done by LIBS. A reference technique was used to validate the quantification abilities: Flame Absorption Spectroscopy (FAAS). The best peak representing each element was found by finding the best correlation between each CCD pixel and the element concentration obtained from the reference technique. The most appropriate peak from LIBS was treated with a normalization procedure to correct for physical matrix effects and small plasma fluctuations. After the LIBS peak was normalized, it was linearly fitted against the data from the reference technique, thus a calibration curve for each element was built. When the normalization procedure was not applied, $\mathrm{R}$ values decreased between $0.1-0.2$ in almost all the elements, however, amongst the results of the calibration curves after the normalization procedure was applied, $\mathrm{R}$ correlation values ranged from 0.8-0.98, which were considered adequate for the elements of interest. The LOD and LOQ values for the LIBS-FAAS models were also calculated and they yielded a range of concentrations that are usually less than the concentrations present in fertilizers produced around the world. Moreover, a cross-validation error analysis was done with LIBS-FAAS, which yielded error values in the range of $8 \%-21 \%$.
\end{abstract}




\section{Resumo}

A capacidade do instrumento Laser Induced Breakdown Spectroscopy (LIBS) foi investigada para a possibilidade de atuar como uma ferramenta de quantificação. Um instrumento de baixo custo fechado do dispositivo de acoplamento de cargas (CCD) foi utilizado a fim de quantificar $\mathrm{K}, \mathrm{Ca}, \mathrm{Mn}, \mathrm{Mg}$, e $\mathrm{Cu}$ presente em 26 amostras de fertilizantes constituídos de diferentes matrizes, alguns fosfato de organomineral e outros de material inorgânico (quantificação de elementos presentes em fertilizante organominerais nunca tinha acontecido). Uma técnica de referência foi utilizada para validar as habilidades de quantificação: Espectroscopia de Absorção Atômica com chama (FAAS). O melhor pico representando cada elemento foi encontrado para produzir a melhor correlação entre cada pixel CCD e a concentração de elementos obtidos a partir da técnica de referência. O pico mais adequado de LIBS foi tratado com um procedimento de normalização, a fim de corrigir os efeitos de matriz e as pequenas flutuações no plasma. Após o pico produzido por LIBS ser normalizado, foi linearmente montado contra os dados de uma técnica de referência e curvas de calibração dos elementos foram construídas. Quando o procedimento de normalização não foi aplicado, valores de $\mathrm{R}$ diminuírem entre 0,1-0,2 em quase todos os elementos. No entanto, entre os resultados produzidos pelas curvas de calibração, após o procedimento de normalização ser aplicado, os valores de correlação $\mathrm{R}$ variaram de 0,8-0,98, o que foi considerado adequado para os elementos de interesse. O LOD e o LOQ para ao modelo LIBS-FAAS também foi calculado e verificou-se que as concentrações produzidas são contrações que normalmente estão abaixo do que se acostumar ver em fertilizantes produzidos em diferentes lugares do mundo. Além disso, uma análise de erro de validação cruzada foi feita com LIBS-FAAS, o que originou valores de erro de $8 \%-21 \%$. 


\section{List of Figures}

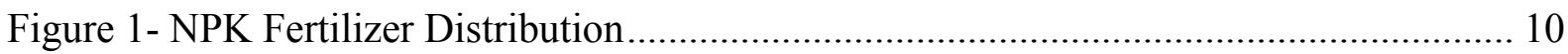

Figure 2 - Fertilizer consumption and Agricultural productivity........................................ 11



Figure 4 - Schematic image of a typical LIBS set-up ..................................................... 14

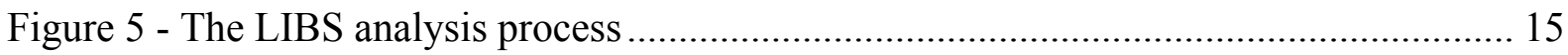

Figure 6 - Linear Fit between AAS and LIBS Intensity for i.) $\mathrm{Cu}$ ii.) $\mathrm{Zn} \mathrm{iii.)} \mathrm{Ca}$.................. 16

Figure 7 - A scatter plot of three principal components (PC1, PC2, and PC3) in component

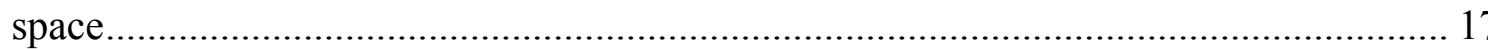

Figure 8 - a) calibration graph b) emission peak c) sample comparison .............................. 19

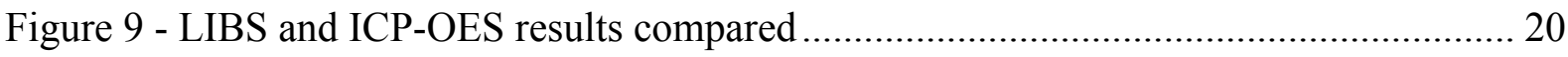

Figure 10 - Linear Fit results between LIBS and ICP-OES for $\mathrm{Cd}, \mathrm{Cr}$, and $\mathrm{Pb}$ in phosphate

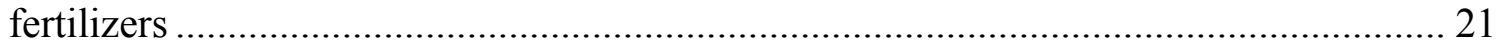

Figure 11 - Calibration between LIBS predicted concentrations and reference concentrations

Figure 12 - Examples of PLS calibration models for (As) and (Cr), respectively.................. 24

Figure 13 - Comparison of LIBS single and double pulse analysis: (a) Double pulse (b) Single pulse

Figure 14 - LIBS bench system model LIBS2500plus: (1) point of energy for laser (2) laser

(3) ablation camera (4) conjunction of spectrometers

Figure 15 - a.) Fitted line under peak to designate region of interest and b.) Lorentzian asymmetrical fit to extract area of the corrected peak .................................................. 32

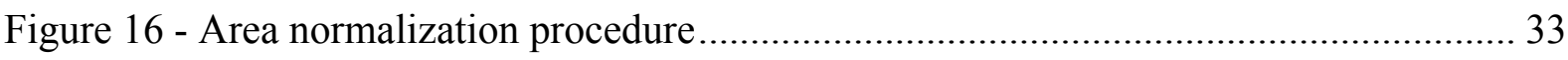

Figure 17 - Pearson correlation analysis between pixel intensity representing $\mathrm{K}$ and reference

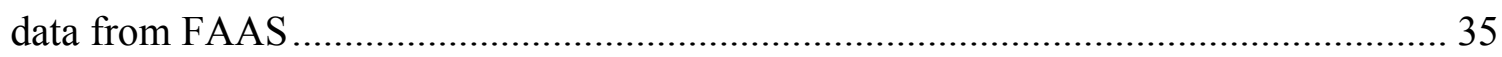

Figure 18 - 150 day measurement of Phosphorus (P) sample ….......................................... 36

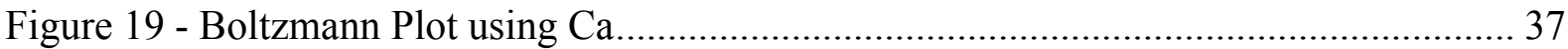

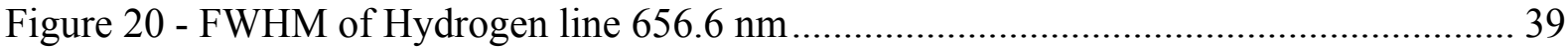

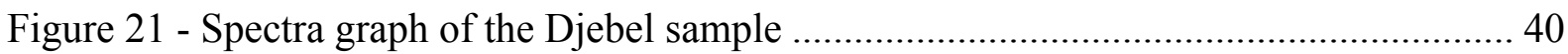

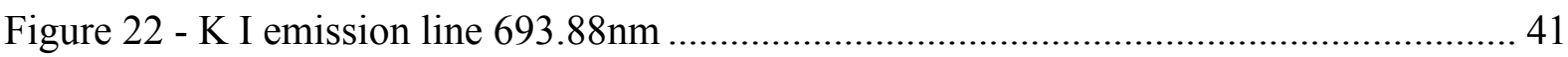

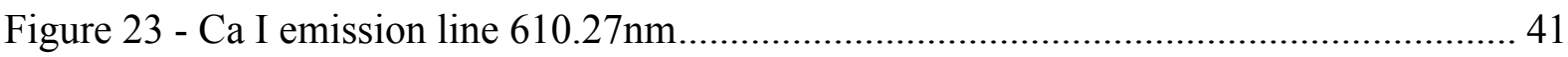

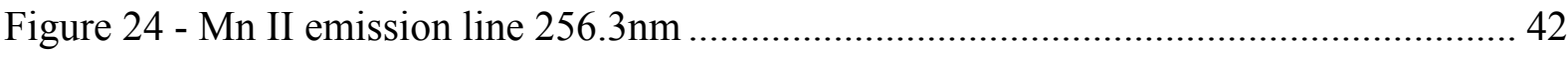

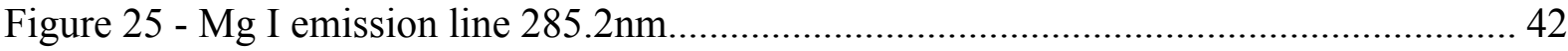






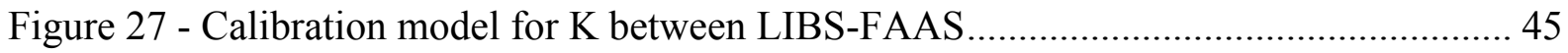

Figure 28 - Calibration model for Ca between LIBS-FAAS ................................................ 45

Figure 29 - Calibration model for Mn between LIBS-FAAS ................................................ 46

Figure 30 - Calibration model for Mg between LIBS-FAAS …........................................ 47

Figure 31 - Calibration model for $\mathrm{Cu}$ between LIBS-FAAS ............................................... 47

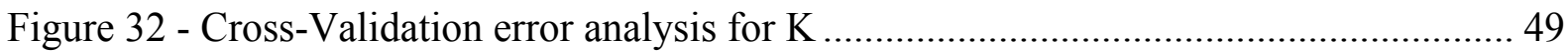

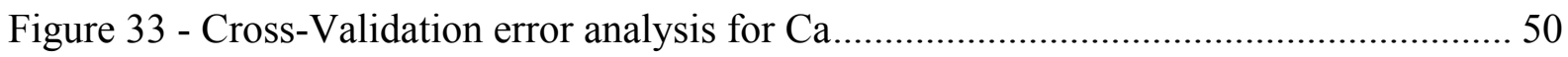

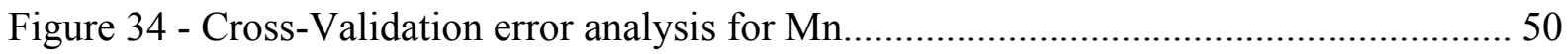

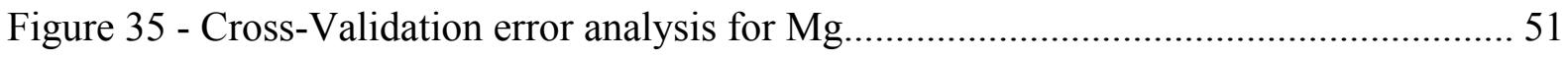

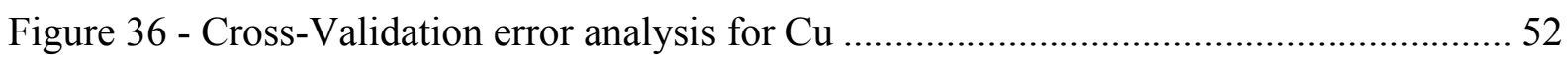




\section{List of Tables}

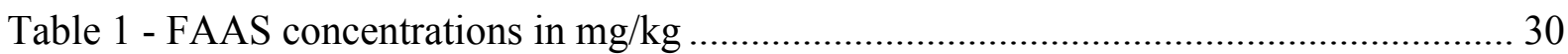

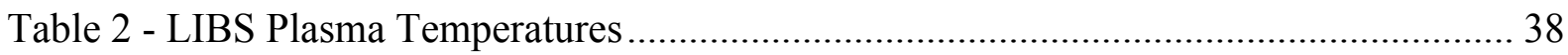

Table 3 - LIBS Plasma Electron Density and LTE conditions ............................................. 39



Table 5 - Summary of calibration curve results with LOD relative to LIBS-FAAS .............. 48

Table 6 - Cross-Validation error analysis for FAAS models................................................ 52 


\section{List of Abbreviations and Symbols}

ANDA - Associação Nacional para Difusão de Adubos

LIBS - Laser Induced Breakdown Spectroscopy

FAAS - Flame Atomic Absorption Spectroscopy

CCD - Charged Coupled Device

$\mathrm{Nd}: Y A G$ - neodymium-doped yttrium aluminum garnet

SAM - Spectral Angle Mapper

NIST - National Institute of Standards and Technology

FWHM - Full Width Half at Maximum

LTE - Local Thermal Equilibrium

$\mathrm{Ne}-$ Electron Density

LOD - Limit of Detection 


\section{Table of Contents}

1 INTRODUCTION $\ldots \ldots \ldots \ldots \ldots \ldots$

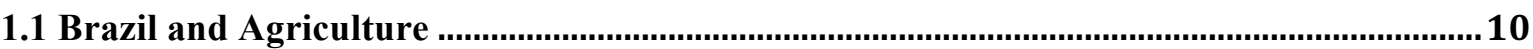

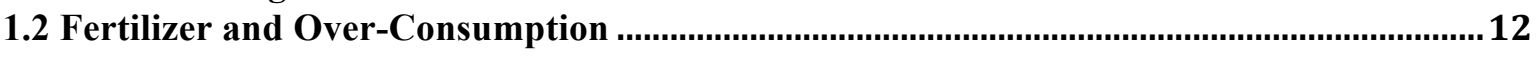

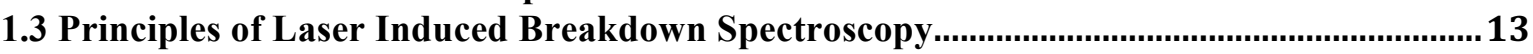



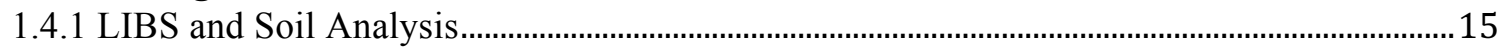

1.4.2 LIBS and Plant Analysis..............................................................................................................

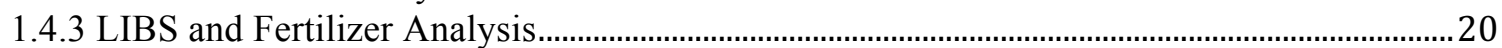





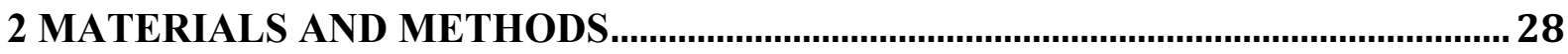

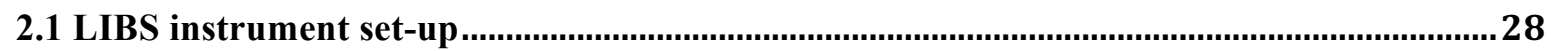

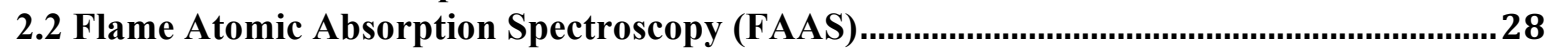

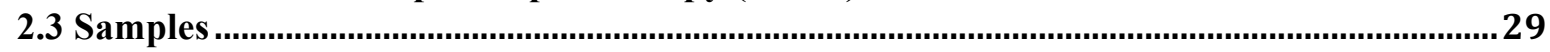



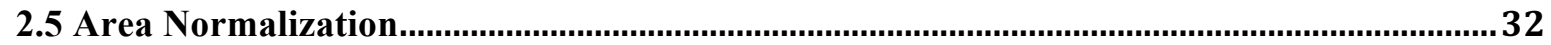

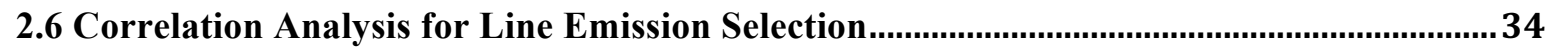

3 RESULTS AND DISCUSSION

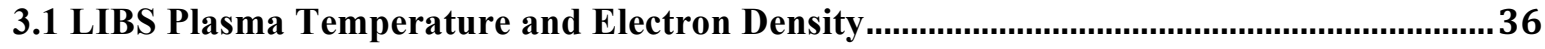

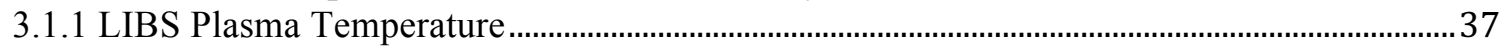

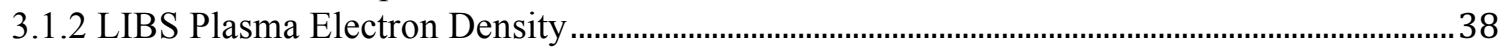

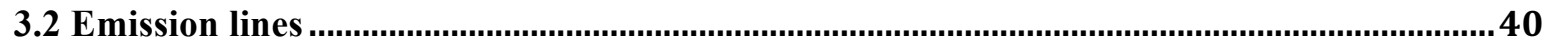

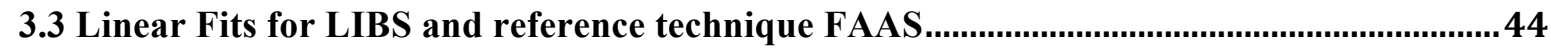

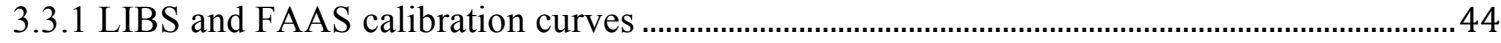

3.4 Cross-Validation error analysis for LIBS and reference technique FAAS .......................48

3.4.1 LIBS and FAAS Cross-Validation analysis ............................................................................. 49

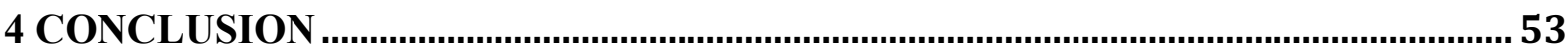

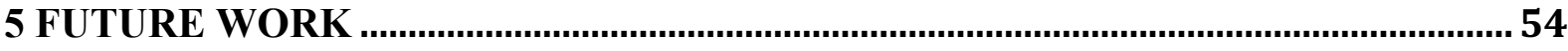

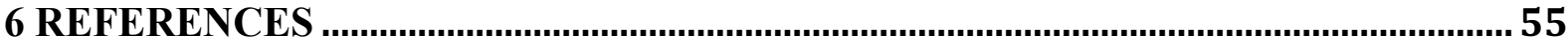




\section{INTRODUCTION}

\subsection{Brazil and Agriculture}

Today's Brazilian economy relies heavily on agricultural production and it is estimated that about $30 \%$ of growth domestic product (GDP) is related to agribusiness. In addition, it is estimated that roughly $50 \%$ of all costs in agribusiness are related to fertilizer and that is mainly due to about $70 \%$ of fertilizer used being imported and extracted from nonrenewable sources. Figure 1 shows a visual of the three most important types of fertilizer and gives an idea to the numbers between how much fertilizer is being imported versus how much is being domestically produced, according to the Associação Nacional para Difusão de Adubos (ANDA), which is a Brazilian organization that reports agricultural statistics, among other things. ${ }^{1}$ The Figure shows two values for each bar in the graph that are separated based on proportionality, for Nitrogen based fertilizers over $75 \%$ is believed to have been imported in 2015 , along with $51 \%$ of phosphorus based fertilizer, and $91 \%$ of potassium based (potash) fertilizer; all these numbers are significant. The values are even more eye opening when the absolute amounts are considered; in 2015 about 3.2Mt (megatons) of nitrogen based fertilizer was used along with 4Mt of phosphorus based and 5Mt of potassium based fertilizer. ${ }^{1}$

Figure 1- NPK Fertilizer Distribution

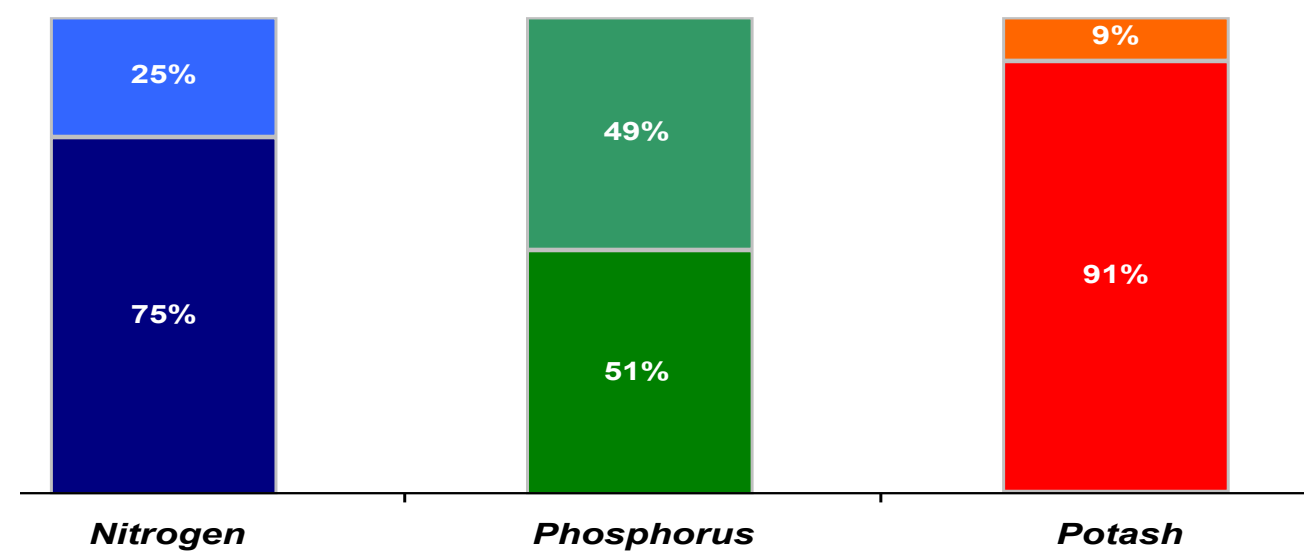

Source: ANDA, 2016, anda.org

Moreover, in recent years, agricultural production has increased at a lower rate than the use of fertilizers, suggesting that a problem with its use might exist. ${ }^{2}$ Figure 2 shows data by ANDA as well, it is a relatively old graph, but it gives an idea of the recent trends in the 
comparison between productivity and fertilizer use. In the last two decades, the use of fertilizer has outpaced the agricultural productivity and as if those statistics weren't alarming enough, the area on which this agricultural activity occurs, has been stagnant for over three decades. Since the 1970's the area, which upon agricultural activity occurs, has endured and increase of its use and this can be confirmed by the increase of fertilizer consumption. ${ }^{1}$ The increase in the amount of fertilizer consumption has a direct influence on the agricultural productivity and if these numbers continue to rise, while the area of agricultural production stays the same, other types of problems that will be discussed going forward can arise.

Figure 2 - Fertilizer consumption and Agricultural productivity



Source: ANDA, 2016, anda.org

Furthermore, another statistic worth noting is the estimation of population growth (Fig. 3). The United States of America Census Bureau estimates that growth will be somewhere around $30 \%$ by 2050 , which means that Brazil will be and even more important contestant in the world stage, in terms of food exportation. ${ }^{3}$ With the increase of population growth, the increase in the agricultural output to help feed the world will also occur, and this means that agricultural productivity and the continued increase in fertilizer consumption will also occur. This type of situation means fertilizer use needs to be more efficient and that new methods of assuring the quality control of fertilizer need to be developed. 
Figure 3 - World population estimates

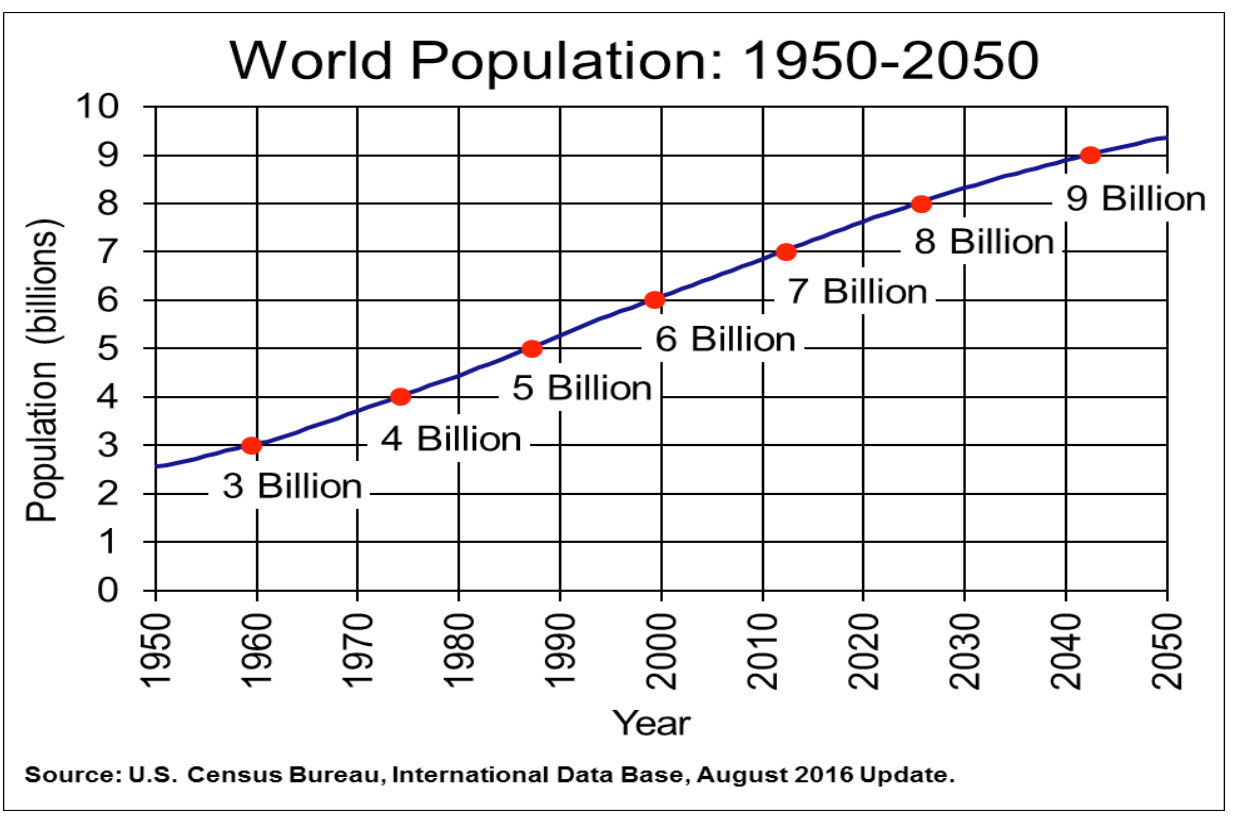

Source: Unites States Census Bureau, 2016, census.gov

\subsection{Fertilizer and Over-Consumption}

The use of large amounts of fertilizer can have negative consequences in the environment if not properly used. The main environmental problem associated with fertilizer use is the contamination that it can cause to water due to nitrates and phosphates that come from the fertilizer. Bacteria in the soils can convert nitrogen into nitrates, which can attach to groundwater and end up in streams or rivers; high levels of nitrogen in drinking water are dangerous for humans. And in relation to phosphates, although they are not dangerous to humans, they cannot be washed out of the soil, because when soil is washed out, the phosphates and the soil wash out together and this combination along with a little water can lead to eutrophication. ${ }^{4}$ Eutrophication is the richness of nutrients in a lake or body of water that causes a dense growth of plant life and leads to the death of animal life, due to the lack of oxygen. Since nitrogen and phosphate based fertilizers are two of the most important along with potassium based fertilizers, the world is not showing interest in slowing down their use or sacrificing profits in order to control the amounts used, thus a method for using these fertilizers more efficiently should be the least that can be done for now. A study done by Vaneechaute C. et. al. (2010) demonstrated the high use of chemical fertilizer in Europe; amounts used reached 10.4 million tons of Nitrogen $(\mathrm{N})$ and 2.4 million tons of Phosphate $(\mathrm{P})$ based fertilizer. ${ }^{5}$ Although this study focuses on the needs of Brazil, it is good to keep in mind that the increase use of fertilizer is worldwide. 
In addition, the increase use of fertilizer also comes with other problems and they relate to the manufactures that produce it. Many times, the manufacturer does not report the accurate concentrations and/or presence of toxic metals; it is up to the government to improve regulations on how imported fertilizer should be analyzed/regulated. Due to the lack of transparency on behalf of some manufactures, studies on the effects of fertilizer on soil are being done worldwide. ${ }^{6-9}$ And even if not all metals present in fertilizer are necessarily harmful, some are harmful if present in large quantities, such as $\mathrm{Mn}, \mathrm{Zn}, \mathrm{Fe}$, and $\mathrm{Mg}$, but there are some metals that even in small quantities can be harmful: $\mathrm{Ni}, \mathrm{Pb}, \mathrm{Co}, \mathrm{Cd}$, and $\mathrm{Hg}$.

\subsection{Principles of Laser Induced Breakdown Spectroscopy}

Conventional LIBS systems are mostly known as being an atomic emission spectroscopic technique capable of analyzing the elemental composition of solid, liquid, and gaseous samples. The features that make this system attractive are: the lack of sample preparation, the quasi non-destruction of the sample, ability to detect both neutral and ion spectral features of the atomic and molecular species present, and the capability for in-situ analysis. ${ }^{10}$

Figure 4 shows a schematic image of a typical LIBS apparatus with a number identifying the different parts of the system. The main components in any LIBS apparatus are: (1) The laser source that produces the pulses for the generation of the plasma, (2) the optical system that focuses the laser pulse onto the target material, (3) the target container where the sample is located, (5) the light collecting system that collects and transports the light emitted by the plasma to the detection system, (6) the spectrometer that provides the spectral signal for analysis, (7) the detector that collects and records the result. ${ }^{11}$ 
Figure 4 - Schematic image of a typical LIBS set-up

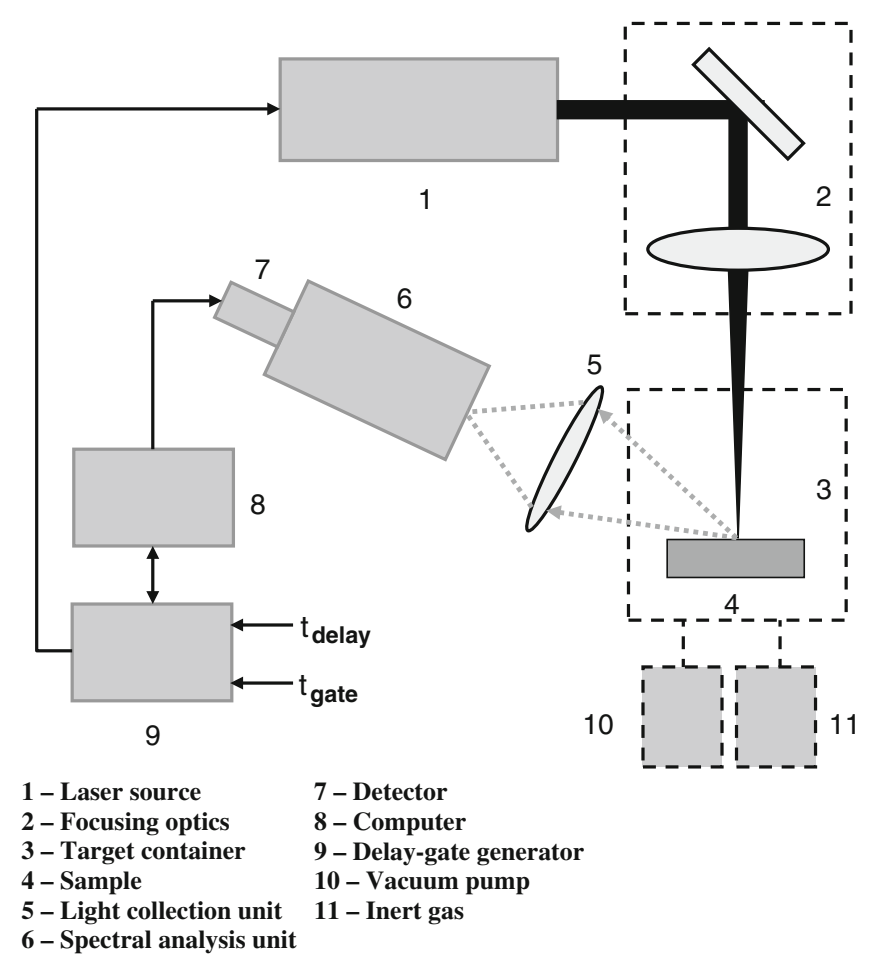

Source: Source: Musazzi, S., 2014, p. 61 License \# 4064010144852

In addition, Figure 5 shows a typical LIBS measurement in a schematic format as well, with numbers showing the order of the process: (1) It starts with a short laser pulse $\left(\mathrm{GW} / \mathrm{cm}^{-2}\right)$ that typically ranges from nanoseconds to femtoseconds and is focused onto a sample in either the solid, liquid, or gaseous state, (2) During the laser shot, a fraction of the produced energy is transferred to matter, which leads to the build-up of high temperature/high-energy plasma with temperatures being around or above $10,000 \mathrm{~K}$, (3) As a result of the plasma formation, continuous electromagnetic radiation is released $(5000 \mathrm{~K}-10000 \mathrm{~K})$, but it is not useful for analysis, (4) electrons then move up into a high energy state, which is followed by them moving back into a lower energy state, where light that is characteristic of an element is emitted, (5) the light is then collected through fiber optics that runs it through a spectrometer, (6) that eventually produces a LIBS raw spectra. ${ }^{12}$ 
Figure 5 - The LIBS analysis process

1.)

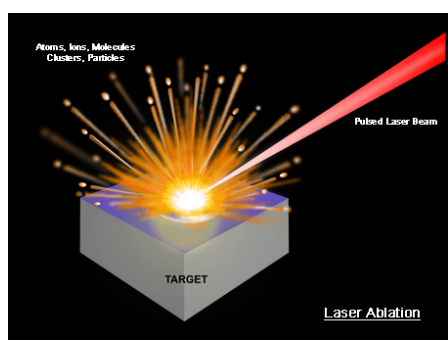

Emitted Light

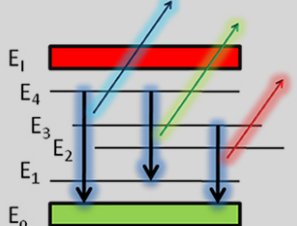

4.)
2.)
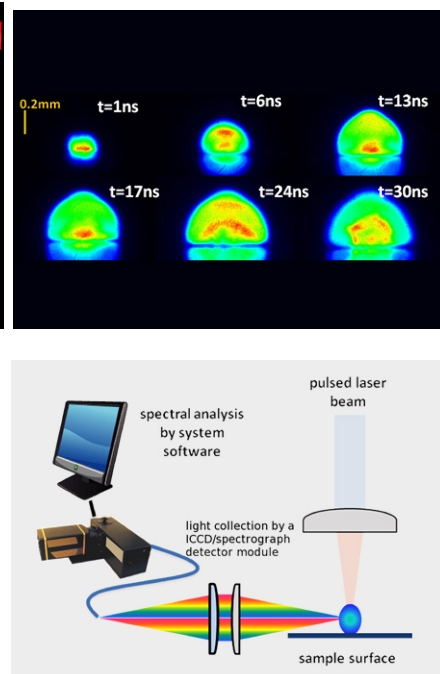

5.)
3.)
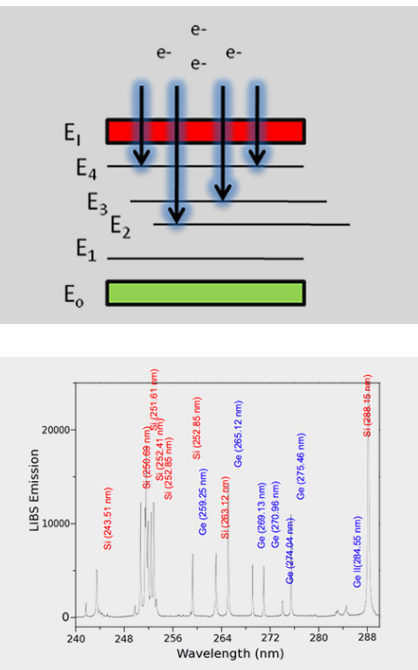

6.)

Source: Applied Spectra, 2004, appliedspectra.com

\subsection{LIBS in Agriculture}

Laser Induced Breakdown Spectroscopy (LIBS), as an instrument of analysis in the area of agriculture, has been gaining more attention lately. Based on recent publications, LIBS has been shown to become an effective instrument with potential advancements in agriculture. We believe that fertilizer analysis is one area where LIBS can play a large role, to improve not only the efficiency of its use, but for monitoring it as well. The use of LIBS in agriculture however, is not limited to its applications on fertilizers; soils and plant analysis are also of great interest when it comes to LIBS.$^{10-11,13-23}$

\subsubsection{LIBS and Soil Analysis}

The application of LIBS to the analysis of soil is more common than its application to other areas of agriculture. It is expected for it to be this way, because soil is as important as plants, animals, rocks, rivers, and anything that is vital to earth. Soil provides different types of habitats for different types of species and it plays a large role in sustaining the life of many organisms by acting as an essential intermediate for maintaining a balance in the ecosystem.

Senesi G. S. and Senesi N. (2016) wrote a review on the measurement of organic carbon (C) in soil using the LIBS instrument. The purpose of their review was to contribute 
knowledge to the current problem of increasing $\mathrm{CO}_{2}$ in the atmosphere, which is related to global climate change. They stated that the first measurement of (C) with LIBS in soil occurred back in 2001, which shows how LIBS has been a relatively recent participant in the area of agriculture. Although it has not been very long since LIBS began to be applied in the field of agriculture, it has had an impact and the production of literature has been continuous. ${ }^{13}$ In a study done by Unnikrishan V. K. et. al. (2013) trace elements in soil of different matrices using LIBS were analyzed. They looked into $\mathrm{Cu}, \mathrm{Zn}$, and $\mathrm{Ca}$, and they determined that in optimal conditions, the ppm concentration of the elements could be done in-situ without interferences. They used Atomic Absorption Spectroscopy (AAS) as a reference technique to confirm their results. The parameters were: number of pulses (420), laser intensity ( $\left.2 \times 10^{12} \mathrm{~W} \mathrm{~cm}^{-2}\right)$, delay time (500 ns), and gate width (600 ns). With these parameters, they claimed the results below and said that they could be reproduced in remote area analysis. $^{14}$

Figure 6 - Linear Fit between AAS and LIBS Intensity for i.) $\mathrm{Cu}$ ii.) $\mathrm{Zn}$ iii.) $\mathrm{Ca}$

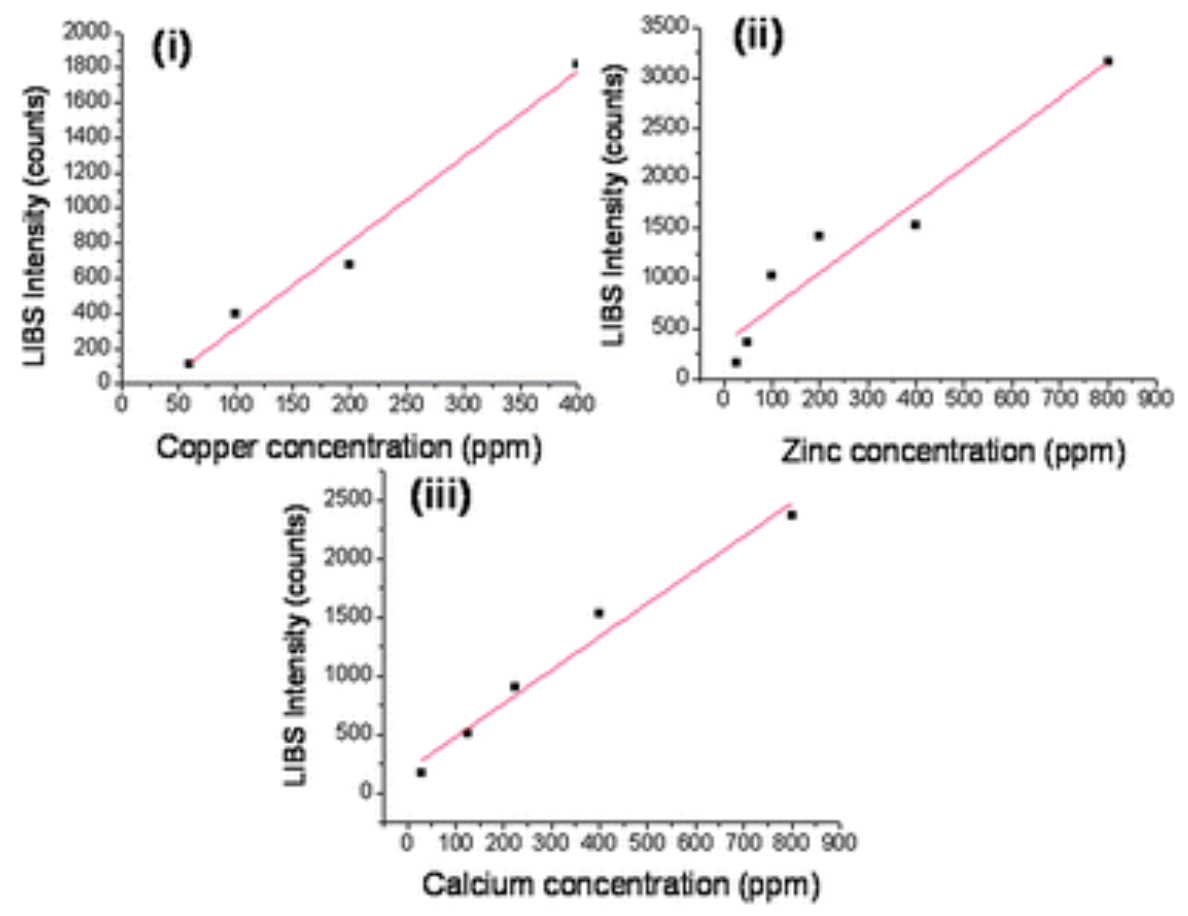

Source: Unnikrishnan, V.K., 2013, p. 1296 License \# 4024060734519

Moreover, in another paper related to LIBS and soil analysis, Kim G. et. al (2013) developed a method involving chemometrics (PLS-DA and PCA) to rapidly screen soils and oils that have been contaminated with heavy metals. They were able to reduce the effects that 
water and grain size have on soil analysis through LIBS by adding an internal standard. They then took the emission lines of various elements and used them as variables in their chemometrics analysis. Three type of soil samples were clearly discriminated by the PCA analysis and a blind test was performed based on the PLS-DA model, which resulted in prediction rates of $100 \%$ for soils contaminated with heavy metals, $100 \%$ for soils contaminated with oils, and $95 \%$ for non-contaminated soils. ${ }^{15}$

Figure 7 - A scatter plot of three principal components (PC1, PC2, and PC3) in component space

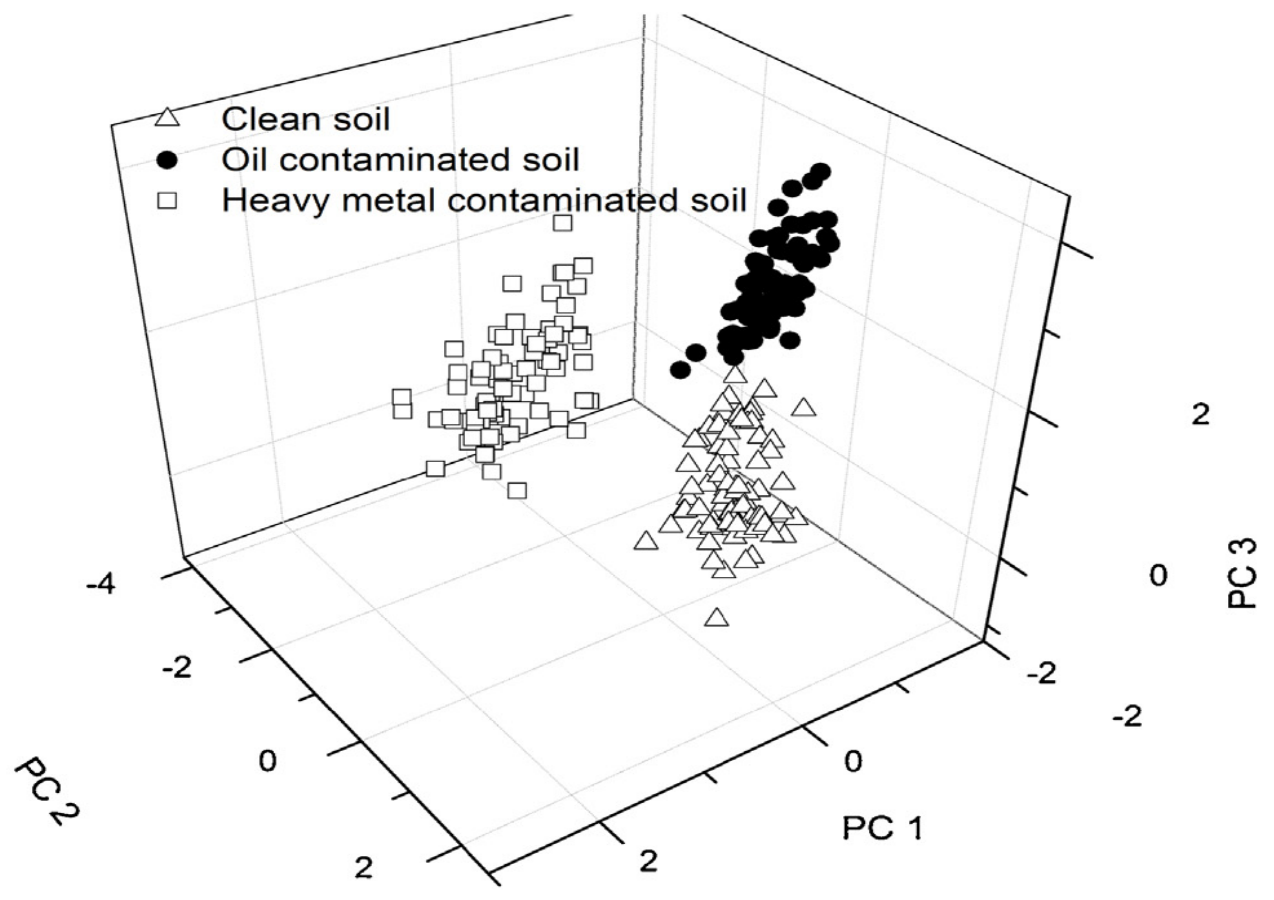

Source: Kim, G., 2013, p. 759 License \# 4021771067311

\subsubsection{LIBS and Plant Analysis}

It makes sense to apply LIBS to the area of plant analysis. A researcher using LIBS to analyze plants would have the same motivation as someone using LIBS for soil or fertilizer analysis, or any other type of analysis with LIBS. The fact that complex sample preparation methods can be avoided and producing results is fast and cheap, the use of LIBS can be attractive to anyone depending on the objective. In terms of plant analysis, LIBS can be very useful in monitoring nutrient status for detecting deficiencies or imbalances, this form of preventative analysis can help agricultural growers in nutrient management and can possibly help prevent something unwanted from happening. 
In a study done by Trevizan L. C. et. al. (2009), LIBS was evaluated for its abilities in the determination of micronutrients of plant materials by using biological certified reference materials for their analytical calibration. The elements of interest were $\mathrm{B}, \mathrm{Cu}, \mathrm{Fe}, \mathrm{Mn}$, and $\mathrm{Zn}$. First the analytical calibration graphs were done using information attained from LIBS relative to the certified reference samples, then the information attained from this model was compared to results obtained from ICP-OES. Figure 8 shows an example of the analysis: $3 \mathrm{a}$ is the calibration graph produced using LIBS and the certified reference samples, $3 \mathrm{~b}$ is the emission line they used, and $3 \mathrm{c}$ is the bar graph comparing the results from the calibration graph and ICP-OES. The study concluded that biological certified reference materials could be used for the building of LIBS calibration models to determine $\mathrm{Cu}, \mathrm{Fe}, \mathrm{Mn}, \mathrm{Zn}$, and $\mathrm{B}$ present in plant materials. The experimental parameters included an Nd:YAG laser operating at $1064 \mathrm{~nm}$ with an energy output of $200 \mathrm{~mJ}$ per pulse and a repetition rate of $10 \mathrm{~Hz}$ was used alongside of an Echelle spectrometer with an ICCD detector. ${ }^{16}$ 
Figure 8 - a) calibration graph b) emission peak c) sample comparison

(a)



(c) (b)

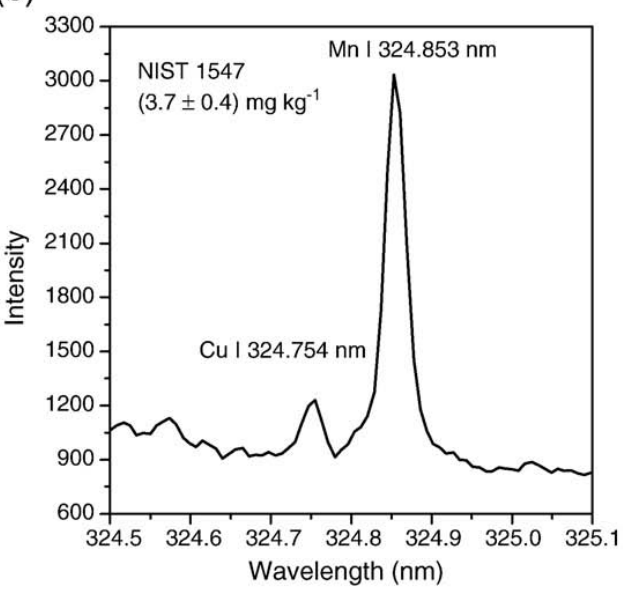



Source: Trevizian, L. C., 2009, p. 372 License \# 4021850460594

In another study pertaining to plant analysis, Nunes L. C. et. al. (2010) optimized and validated a LIBS method for the determination of macro and micronutrients present in sugar cane leaves. The instrument was applied towards the determination of the macronutrients $(\mathrm{P}$, $\mathrm{K}, \mathrm{Ca}, \mathrm{Mg}$ ) and micronutrients $(\mathrm{B}, \mathrm{Cu}, \mathrm{Fe}, \mathrm{Mn}$, and $\mathrm{Zn})$. The operational conditions were optimized: an Nd:YAG laser at $1064 \mathrm{~nm}$ with $100 \mathrm{~mJ}$ output power per pulse was used. Emission intensities were measured after $2.0 \mu$ s (delay time) with an integration time gate of 4.5 $\mu$ s. Quantification was done by univariate and multivariate calibration and chemometric methods, such as Partial Least Squares Regression (PLSR) and interval Partial Least Squares (iPLS). Calibration models of 26 laboratory samples and its validation from 15 test samples were compared to data from ICP-OES and the LIBS data did not differ significantly. They concluded that LIBS is a useful tool of analysis for elements present in plant materials when choosing a calibration and validation samples with a similar matrix composition. Figure 9 
shows LIBS results from its multivariate analysis compared to results obtained by ICP-OES, and as you can see they are within a small error difference. ${ }^{17}$

Figure 9 - LIBS and ICP-OES results compared
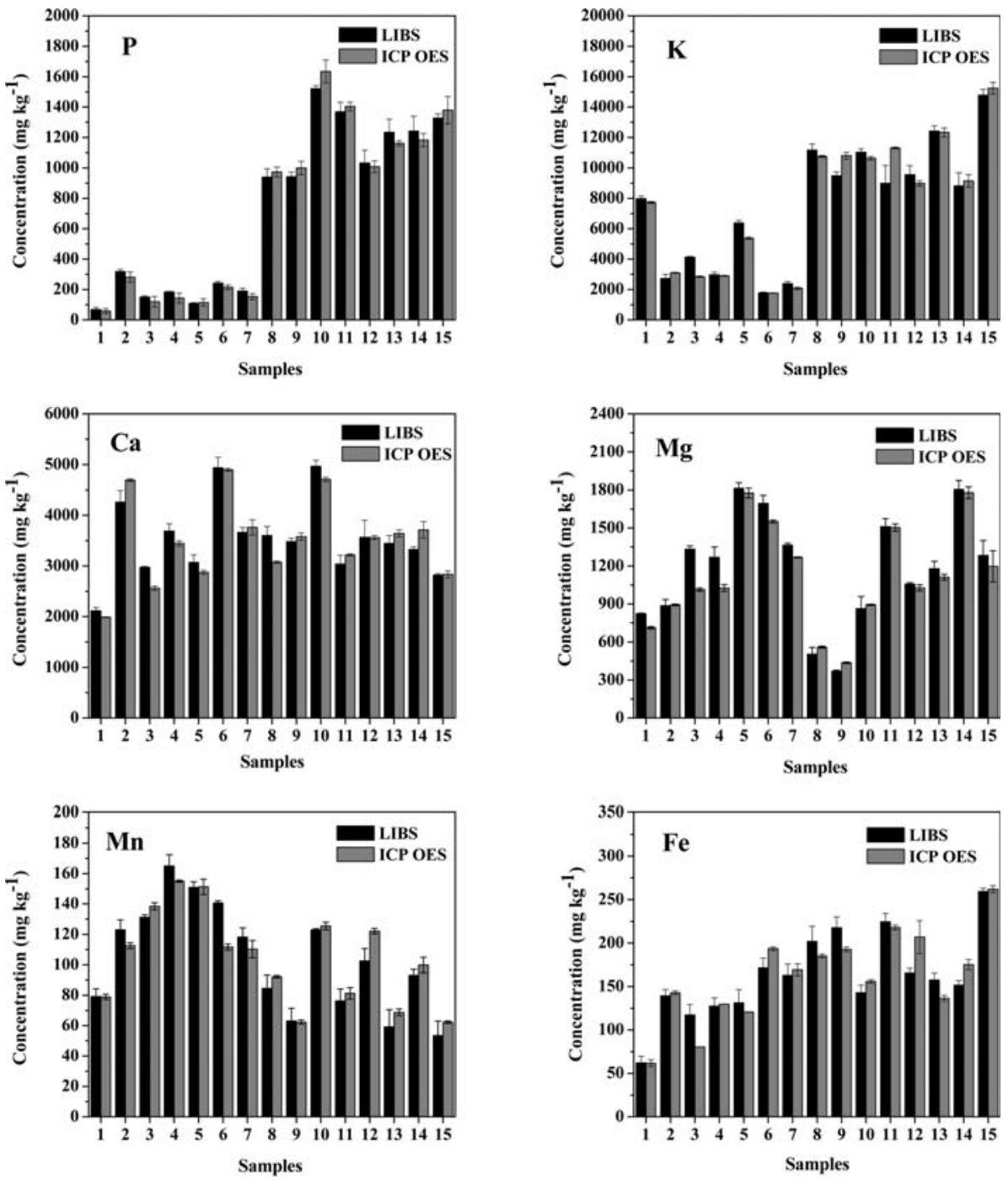

Source: Nunes, L. C., 2010, p. 1459 License \# 4024060402268

\subsubsection{LIBS and Fertilizer Analysis}

LIBS for fertilizer analysis is the main goal of this dissertation project and is an area that has not been thoroughly explored. There are studies of LIBS analyzing fertilizers, but it is less than in other areas related to agriculture and there is also a lack of diversity in the studies. For example, there has not been a study that corrects for differences in the matrix of the fertilizer and it is known that the LIBS instrument produces results that can be heavily influenced by the make-up of a sample. ${ }^{18}$ This study proposes a method that can correct for 
matrix effects and more specifically for organic-mineral fertilizers, which is something that has not been done yet elsewhere.

In a relevant study for us, Nunes L. C. et. al. (2014) validated a method for the quantitative determination of toxic elements $(\mathrm{Cd}, \mathrm{Cr}, \mathrm{Pb})$ in phosphate fertilizer; 30 phosphate fertilizer samples and 2 reference materials (NIST SRM 695 and BCR 032) were used for developing the method. A Q-switched Nd:YAG laser at 1064nm which generated $5 \mathrm{~ns}$ pulses of up to $365 \pm 3 \mathrm{~mJ}$, in a $6 \mathrm{~mm}$ diameter beam at a rate of $10 \mathrm{~Hz}$ was used. Calibration curves were obtained; the peak area of the corrected maximum intensities of the line emitted by the analyte against the reference concentrations found by using ICP-OES were analyzed by using a classical least squares regression model. Correlation between emission signals (peak areas) with assigned mass fractions yielded good results for $\mathrm{Cd}, \mathrm{Cu}$, and $\mathrm{Pb}$. The correlation coefficients ranged from 0.9585 to $0.9930 .^{19}$

Figure 10 - Linear Fit results between LIBS and ICP-OES for $\mathrm{Cd}, \mathrm{Cr}$, and $\mathrm{Pb}$ in phosphate fertilizers
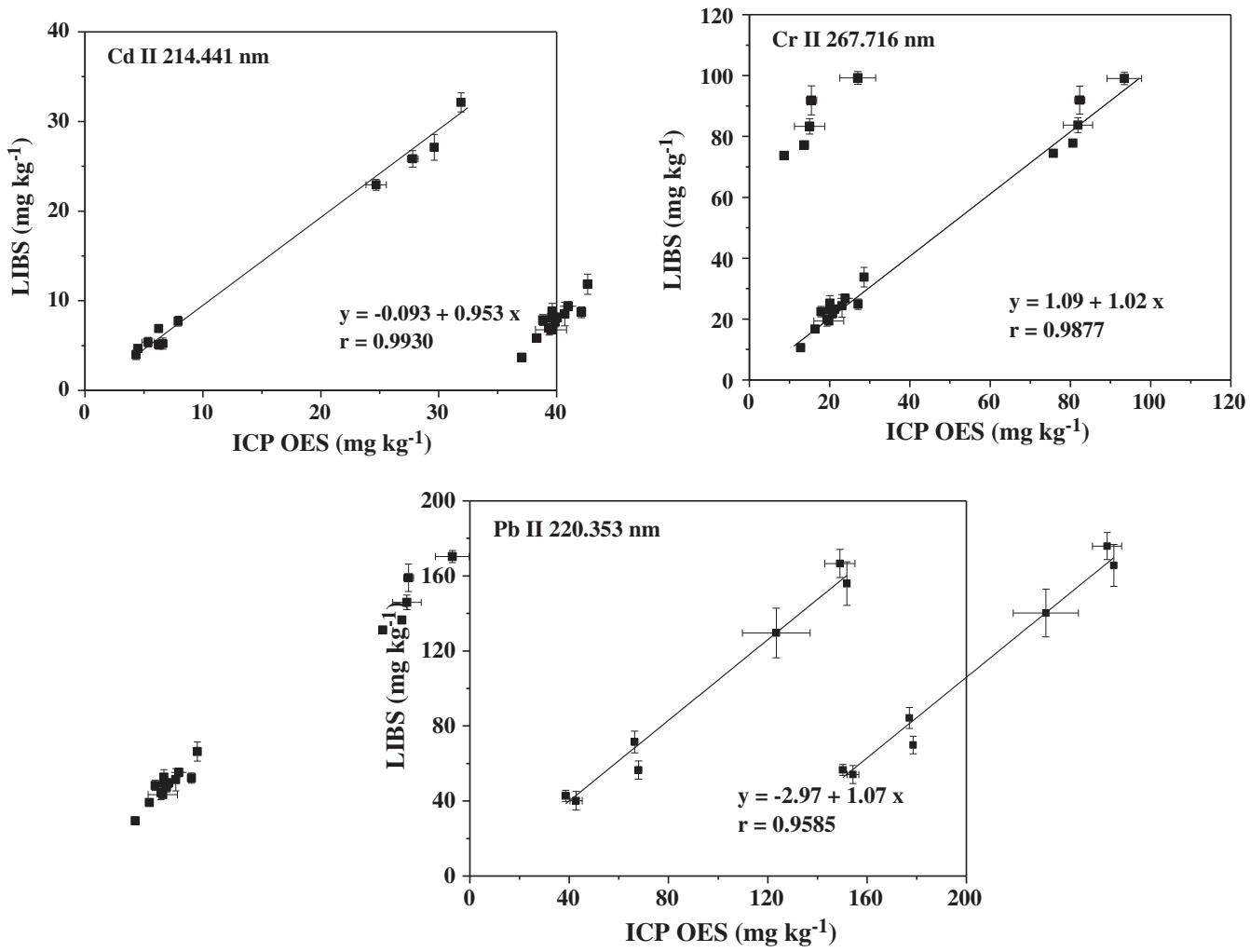

Source: Nunes, L. C., 2014, p. 46 License \# 4021860699960

This work has a similar draft to this dissertation project, but the analysis here was extended a bit further. The project shows not only the determination of elements in phosphate fertilizer, but in organic based fertilizer as well with macronutrient $\mathrm{K}$ and micronutrients $(\mathrm{Mn}$, $\mathrm{Mg}, \mathrm{Ca}, \mathrm{Cu}$ ) being evaluated. 
In another interesting study that is related to fertilizer, Yao S. et. al. (2010) analyzed a set of 11 fertilizers containing different concentrations of phosphorus and potassium. They built calibration models for Phosphorus and Potassium through the method of partial least squares (PLS), which is a known multivariate calibration method. They then validated the predicted concentrations produced by the models, by comparing them to reference concentrations, which confirmed that the LIBS technique has a good potential for determination of elements present in fertilizer. Their experimental parameters consisted of a $532 \mathrm{~nm}$ Q-switched Nd:YAG laser that ran a repetition rate of $1 \mathrm{~Hz}$, with a $8 \mathrm{~ns}$ laser pulse at an output energy of $70 \mathrm{~mJ}$. Their study concluded that the LIBS models produced a high correlation and could successfully predict the concentration of $\mathrm{P}$ and $\mathrm{K}$ when LIBS is combined with PLS and a multivariate calibration is performed. Figure 11 shows correlation models between the $\mathrm{P}$ reference concentration and the LIBS predicted concentration and between $\mathrm{K}$ reference concentration and LIBS predicted concentration; there are two lines on the graphs, the solid line with the solid squares represents the calibration model and the dotted line with open squares represents the resulting validation. ${ }^{10}$

Figure 11 - Calibration between LIBS predicted concentrations and reference concentrations
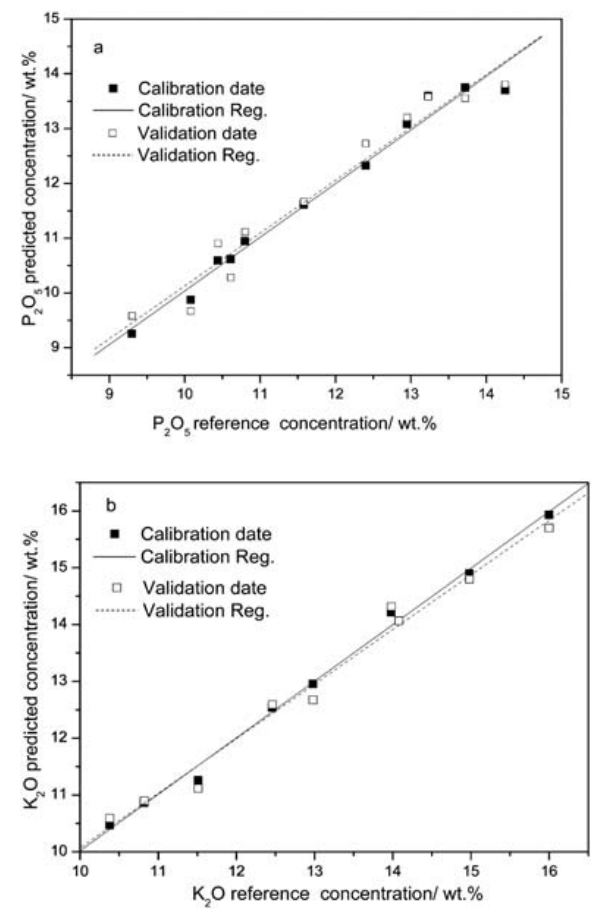

Source: Yao, S., 2010, p. 1736 License \# 4024061236177 
All the studies mentioned show some of the recent interest that has been gaining in applying LIBS to agriculture, however, it should be noted that the application of LIBS to fertilizer, is an area where there is a little amount of literature when compared to soil and plant analysis. More specifically, there are no studies pertaining to LIBS in the analysis of organic-mineral fertilizer, which is an area we are acting on. Most of the work out there related to LIBS and agriculture is in the analysis of soil and Musazzi S. et. al. (2014) mentioned how the biological and chemical properties of soil are changing due to human industrialization, thus this area is a vital part of a countries socioeconomic branch. ${ }^{11}$ And although it makes sense that there are more studies on soil, we believe that due to population growth and the increase use in fertilizer, increasing the amount of studies in fertilizer analysis with LIBS is becoming just as important.

\subsection{LIBS Current and Recent Developments}

Due to the advantages of LIBS, the development of the instrument has been of interest to many research groups around the world. Some of the advantages that make this instrument interesting begin with its ability to analyze with little or no sample preparation, and this characteristic alone is attractive to any researcher. The instrument is also a fast-acting system, cost-efficient, and can analyze elements simultaneously, while using a small sample size $(0.1 \mu \mathrm{g}-1 \mathrm{mg})$. Another great characteristic is its ability to analyze samples in the solid, liquid, or gaseous state. Moreover, when compared to other spectroscopic techniques (ICP-OES and AAS), it also has advantages over them, such as a minimally-destructive method since it uses a small sample mass, it does not heat the surrounding material which disregards the use of cooling systems, it has a heterogeneity sample detection capability due to the small laser focus area, and it has the possibility of remote operation such as surface mapping and depth soil analysis.

Currently, this instrument is in a time of growth, it has produced vast amounts of literature in the last decade and the trend is growing. ${ }^{11,24}$ The instrument is dynamic in the types of areas that it participates; some noteworthy areas are remote area analysis, explosives, and nuclear materials. ${ }^{23}$ With technological advancements it is becoming easier to attain low cost lasers with high potency that can perform at high speeds and there are a number of papers that focus on plasma physics, optics, and the electrical components of LIBS; it is studies like these that establish promise in its use, thus it is what has led to its increased interest in the last decade. $^{25}$ 
Moreover, LIBS does however, have its disadvantages because the technique is dependent upon the intensity of the atomic spectrum obtained through the sample and the roughness of the high-powered laser, which hampers repeatability of the measurement and quantification of the material. There is also the possibility of interference effects amongst elements due to the resolution of the spectra. And another problem with the technique is that its limit of detection (LOD) is not as good as in well-established techniques.

In terms of the systems quantification abilities, developing this area is becoming more common and has had some success with the help of chemometrics, which greatly reduces some of the impacts caused by its disadvantages. ${ }^{11,21,26-29}$ Mukhono et. al. (2013) can serve as an example of measuring element concentration with LIBS. They attained rock and soil samples from a geothermal field for the quantification of heavy metals by applying multivariate chemometric methods to reduce spectral complexity brought upon by the high background radiation area in which their samples were found. The elements $\mathrm{As}, \mathrm{Cr}, \mathrm{Cu}, \mathrm{Pb}$, and Ti were modeled for direct quantification using partial least squares (PLS) and artificial networks (ANN), the authors stated that using ANN was better than PLS, because it performed better in modeling nonlinear relationships using the non-linear in-built functions, however, PLS was also a good model over the univariate approach because it allowed all the spectral regions with chemical content of the elements of interest to consider line shape, spectral interference, and broadening. ${ }^{27}$ Furthermore, they also validated their results using the LIBS predicted values and as you can see in Figure 12 the elements As and Cr were nicely correlated with the known concertation samples.

Figure 12 - Examples of validation models for (As) and (Cr), respectively
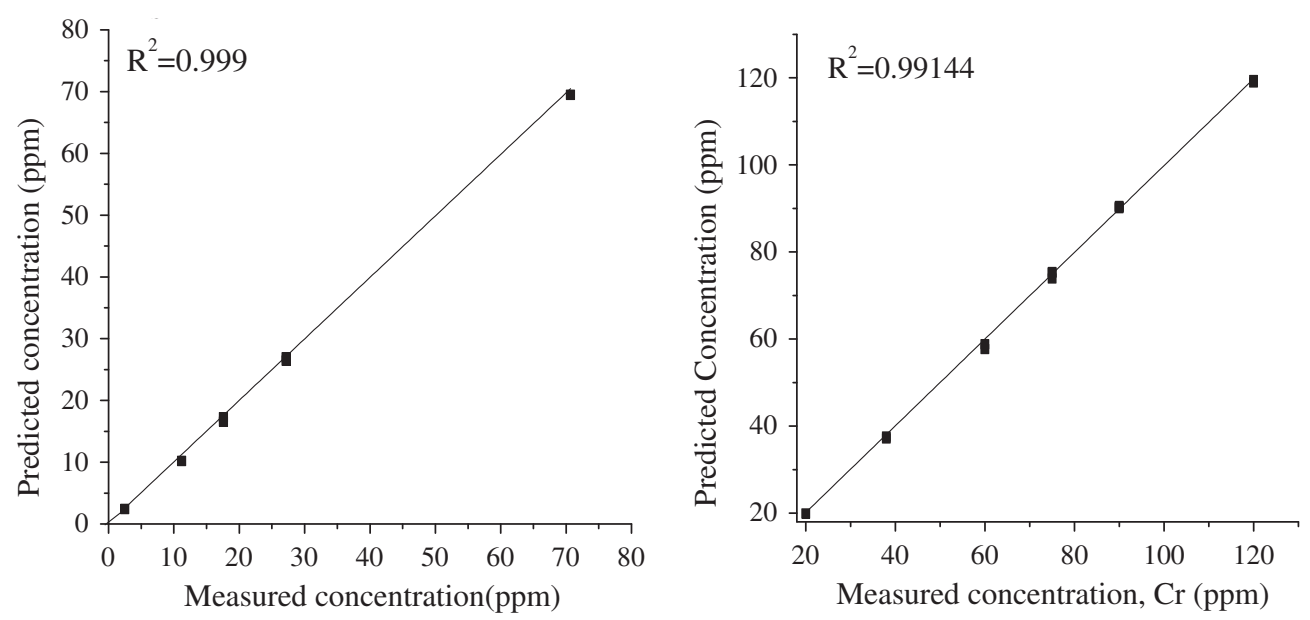

Source: Mukhono, P. M., 2013, p. 82 License \# 4021861094845 
In another study, Zhang et. al. (2015) evaluates the matrix effects in laser ablation, which is another common issue that hinders the quantification abilities of LIBS. His team analyzed 23 solid standards of six types of metal matrices (Al, Fe, Ni, Zn, W) and emphasized the influence of laser pulse duration on analysis. Nanosecond (ns) and Femtosecond (fs) lasers that had a buffer-gas-assisted ionization source coupled with an orthogonal time-of-flight mass spectrometer were used, relative sensitivity coefficients were then calculated and combined with the physical property values of the matrices to form a dataset. The dataset was analyzed by the chemometrics tools of orthogonal partial-least squares (OPLS) and it was found that thermal properties of solids play vital roles in the matrix effect induced by ns-laser ablation, while in fs-laser ablation the effect on the matrix is much less. This study gives researches a new avenue of analysis when trying to correct for matrix effects. ${ }^{28}$

Furthermore, the capabilities of LIBS have gained the interest of NASA (National Aeronautics and Space Administration) in a significant way. NASA's very popular recent mission, that sent a robot named "Curiosity" to Mars, is equipped with a LIBS system (ChemCam). There is no doubt that the system was chosen not only for its abilities to characterize the Martian soil, but also because of its ability for remote analysis. Roger Wiens of the Los Alamos National Laboratory, who is the principal investigator of the ChemCam instrument, said the instrument was designed to do a rapid chemical and visual reconnaissance of rocks and soils around the rover. The ChemCam instrument contains a LIBS system and in the first two years on MARS, the instrument has returned over 160,000 LIBS spectra on 4500 locations, along with 2600 high-resolution images; these are all available to the public. He also went on state that there are more than 20 papers in press or in the process of publication. ${ }^{29}$ The fact that NASA's project decided to work with the LIBS instrument over other types of instruments of elemental analysis, says a lot about the technique.

Boucher et. al. (2015) states that the key to interpreting Martian soil or any other type of LIBS data are calibrations that relate laboratory standards to unknowns examined in other settings, this helps us to enable predictions of chemical compositions. Boucher et. al. (2015) did a study where they analyzed LIBS spectral data using linear regression methods including PLS-1 and PLS-2, Principal Component Regression (PCR), least absolute shrinkage and selection operator (lasso), elastic net, and linear support vector regression (SVR-Lin). The methods were compared against results from nonlinear regression methods including kernel Principal Component Regression (K-PCR), Polynomial Kernel Support Vector Regression (SVR-Py) and k-Nearest Neighbor $(\mathrm{kNN})$ to detect the most effective models for interpreting chemical abundances of LIBS spectra attained from geological samples. ${ }^{29}$ Although we don't 
plan to apply as much chemometrics as Boucher's team did, it does demonstrate the interest of chemometrics applications for the correction of matrix effects in elemental analysis.

Other interesting and recent developments in LIBS include the introduction of the double pulse system ${ }^{30-31}$, which consists in applying a second pulse with a delay of a few microseconds, the pulse is reabsorbed by the plasma, improving the quality of the broadcast signal. Ahmed R. and Baig M. A. (2009) did a comparative study between single and double pulsed laser induced breakdown spectroscopy for singly ionized lines. A standard 1064nm wavelength laser was used for the single pulse analysis and for the double pulse analysis, but the double pulse analysis used a second collinear laser at 532nm (Nd:YAG). The study showed that the double pulse collinear system yielded a significantly greater signal when compared to the single pulse system when analyzing singly ionized lines. Figure 13 shows a comparison of a LIBS analysis with single and double pulse parameters. ${ }^{30}$ Moreover, although it is a fact that the double pulse system does indeed produce clearer and more intense signals as shown in this study, it is still not a viable option for replacing our choice of using the LIBS single pulse system. The single pulse system can be used in remote analysis, which is one of the main reasons that it was chosen for the ChemCam (Mars rover) system. ${ }^{32}$

Figure 13 - Comparison of LIBS single and double pulse analysis: (a) Double pulse (b) Single pulse

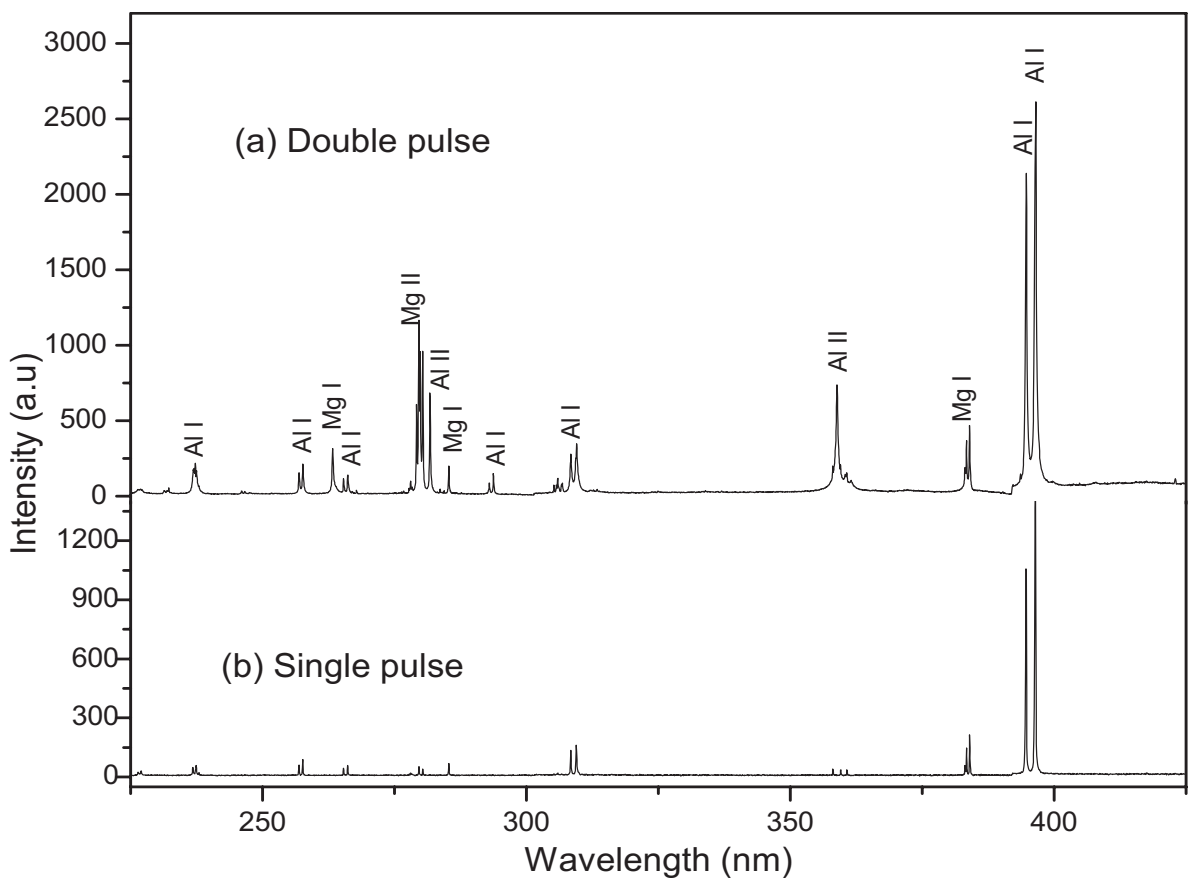

Source: Ahmed, R., 2009, p. 2 With the permission of AIP Publishing 
An area where the double system has been applied and is probably more popular to use in, when compared to the single pulse system, is in the detection of liquids. ${ }^{33-34}$ The reason the double pulse system can be more popular with liquid analysis is because the signal can be weak when using a single pulse system and it is actually one of the disadvantages of the single pulse system. Another area where it has been applied is in agriculture, where Nicolodelli et. al. (2015) optimized parameters on a LIBS double pulse system in the analysis of soil. ${ }^{35}$ Even though double pulse systems have proven to produce much better peak signals when compared to single pulse systems such as the one used for this study, it must be noted that a key goal for developing methods of analysis, is that they must be apt for in-situ activity. Unfortunately, double pulse systems are too complex and not equipped for in-situ analysis and so it wasn't of interest for this project. Moreover, it is safe to say that further advancements are going to include the miniaturization of components and the development of portable equipment for in-situ analysis in remote conditions. ${ }^{25,36-37}$

\subsection{Objectives}

The purpose of this dissertation was to develop a method of quantification for the macronutrient: $\mathrm{K}$ and micronutrients: $\mathrm{Mn}, \mathrm{Mg}, \mathrm{Ca}$, and $\mathrm{Cu}$ in different types of fertilizer by using LIBS. The goal was to show that LIBS could act as an adequate quantification system of elements present in fertilizers of different matrices in a more efficient and practical manner. With practicality and efficiency, it is believed that the method proposed here could lead to success for in-situ analysis in remote settings. And using a reliable method of quantification, such as Flame Atomic Absorption Spectroscopy (FAAS) we wanted to demonstrate our hypothesis. 


\section{MATERIALS AND METHODS}

\subsection{LIBS instrument set-up}

The system used for this project (Fig. 14) was a commercial LIBS instrument (2500 Ocean Optics) that consisted of a Q-switched Nd:YAG laser (Quantel operating at a wavelength of $1064 \mathrm{~nm}$ ) with a repetition rate of $10 \mathrm{~Hz}$, a laser pulse of $8 \mathrm{~ns}$, and an energy output of $60 \mathrm{~mJ}$ with an integration time of $2.1 \mathrm{~ms}$. The size of the laser spot hitting the sample was estimated to be around $100 \mu \mathrm{m}^{9}$. The plasma emission was collected by a fiber optics bundle, which then delivered incoming light to seven spectrometers $(190-966 \mathrm{~nm})$ at an optical resolution of $0.1 \mathrm{~nm}$. The detector used consisted of a non-gated charge coupled device (CCD) with 2048 pixel array.

Figure 14 - LIBS bench system model LIBS2500plus: (1) point of energy for laser (2) laser (3) ablation chamber (4) conjunction of spectrometers



Source: Self-Authorship

\subsection{Flame Atomic Absorption Spectroscopy (FAAS)}

The reference technique used was Atomic Absorption Spectroscopy (AAS). It is a spectral-analytical system that can quantitavely determine elements. Quantification of elements is done through absorption of optical radiation (light) by free atoms in the gaseous state. The samples must be atomized, which is usually done by a flame or electro-thermal 
atomizer. It is then followed by the atoms being irradiated by optical radiation, which are then passed through a monochromator to separate any other radiation belonging to other sources.

The system used for this work was a Perkin-Elmer PinAAcle 900T model, which is a flame type of AAS and uses an infrared lamp. The sample preparation process for this phase required the digestion of a $1 \mathrm{~g}$ sample in $10 \mathrm{~mL} \mathrm{HNO}_{3}: 3 \mathrm{~mL} \mathrm{H}_{2} \mathrm{O}_{2}$ solution for six hours in a digesting block at $150^{\circ} \mathrm{C}$.

\subsection{Samples}

All samples used in the actual LIBS analysis were grounded and sieved ( $<100$ mesh) to ensure homogeneity, which followed with the powders being pressed at $6 \times 10^{8} \mathrm{~N} . \mathrm{m}^{-2}$ for $30 \mathrm{sec}$ to obtain a sample in pellet form. Each sample pellet experienced 30 laser shots on each side, for a total of 60 laser shots, but sample analysis began with a blank shot (laser shot with no sample) to help correct for the offset caused by background noise.

Three main type of fertilizer samples are used in this work: 5 phosphate rocks of different sources: Bayovar, Gafsa, Arad, Djebel and Itafos; 3 commercial mineral fertilizers: Monoammonium phosphate (MAP), single superphosphate (SS) and triple superphosphate (TS); 18 organic-mineral fertilizers consisting of mixtures of $60 \%$ poultry litter either noncomposted (PL) or composted (CPL) with 40\% MAP; some samples had 2\% bentonite and various amounts of Sulphur (S) (from 1 to $10 \%$ ).

\section{Mineral Fertilizers:}

- MAP (Monoammonium Phosphate)

- S.S (Single Superphosphate)

- S.T. (Superphosphate Triple)

\section{Phosphate based samples:}

- Arad Natural Phosphate

- Djebel Natural Phosphate

- Bayovar Natural Phosphate

- Itafos Natural Phosphate

- Gafsa Natural Phosphate

\section{Organomineral Fertilizers:}

- Organomineral A: Natural Poultry Litter + MAP 
- Organomineral B: Composted Poultry Litter + MAP

- Organomineral C: Natural Poultry Litter + MAP

- Organomineral D: Natural Poultry Litter + Bayovar

- Organomineral E: Natural Poultry Litter + MAP

- Organomineral F: Composted Poultry Litter + MAP

- Organomineral G: Natural Poultry Litter + MAP

- Organomineral H: Natural Poultry Litter + MAP

- Organomineral I: Composted Poultry Litter + MAP

- Organomineral J: Composted Poultry Litter + Map + Silicate

- Organomineral K: Natural Poultry Litter + Map + 1\% Sulphur (S) + bentonite

- Organomineral L: Natural Poultry Litter + Map + 1\% (S) + bentonite

- Organomineral M: Natural Poultry Litter + Map + 5\% (S) + bentonite

- Organomineral N: Natural Poultry Litter + Map + 10\% (S) + bentonite

- Organomineral O: Natural Poultry Litter + Bayovar

- Organomineral P: Composted Poultry Litter + Bayovar

- Organomineral Q: Natural Poultry Litter + Phosphate

- Organomineral R: Composted Poultry Litter + Phosphate

Furthermore, the concentrations of all the elements are shown in the table below in $\mathrm{mg} / \mathrm{kg}$ units. These concentrations were attained using the reliable method of Flame Atomic Absorption Spectroscopy and were used to build calibration models.

Table 1 - FAAS concentrations in $\mathrm{mg} / \mathrm{kg}$

\begin{tabular}{|c|c|c|c|c|c|}
\hline Samples & $\boldsymbol{K}$ & $\boldsymbol{C a}$ & $\boldsymbol{M n}$ & $\boldsymbol{M g}$ & $\boldsymbol{C u}$ \\
\hline MAP & 22.59 & 4.07 & 1.37 & 39.42 & 0.05 \\
\hline SS & 145.30 & 936.03 & 3.29 & 22.44 & 1.52 \\
\hline ST & 18.98 & 408.11 & 0.61 & 32.08 & 0.43 \\
\hline Arad & 17.16 & 1336.60 & 0.74 & 16.68 & 0.46 \\
\hline Dejebel & 11.34 & 1823.31 & 0.43 & 41.74 & 0.21 \\
\hline Bayovar & 20.88 & 1602.99 & 4.18 & 30.34 & 1.78 \\
\hline Gafsa & 8.12 & 1783.62 & 0.51 & 29.98 & 0.20 \\
\hline Itafos & 88.97 & 1508.22 & 4.16 & 32.46 & 1.07 \\
\hline A & 500.90 & 151.10 & 4.05 & 27.54 & 0.73 \\
\hline
\end{tabular}




\begin{tabular}{|c|c|c|c|c|c|}
\hline$B$ & 203.60 & 169.89 & 4.64 & 26.84 & 0.76 \\
\hline$C$ & 11.42 & 501.90 & 1.33 & 37.74 & 0.51 \\
\hline$D$ & 136.34 & 657.09 & 5.90 & 37.9 & 1.32 \\
\hline$E$ & 108.18 & 137.13 & 4.22 & 23.3 & 0.62 \\
\hline$F$ & 124.20 & 178.79 & 5.03 & 27.32 & 0.81 \\
\hline$G$ & 139.46 & 109.54 & 4.56 & 26.06 & 0.68 \\
\hline$H$ & 123.24 & 150.00 & 4.33 & 24.04 & 0.66 \\
\hline$I$ & 164.88 & 205.36 & 5.81 & 29.02 & 0.92 \\
\hline$J$ & 107.46 & 80.26 & 2.10 & 27.28 & 0.30 \\
\hline$K$ & 141.90 & 118.04 & 4.38 & 22.84 & 0.62 \\
\hline$L$ & 114.80 & 117.59 & 4.44 & 22.82 & 0.60 \\
\hline M & 128.10 & 113.99 & 4.65 & 23.78 & 0.64 \\
\hline$N$ & 117.60 & 106.49 & 4.18 & 22.66 & 0.55 \\
\hline$O$ & 118.90 & 1034.02 & 6.36 & 34.28 & 0.60 \\
\hline$P$ & 176.50 & 867.56 & 8.65 & 38.66 & 1.01 \\
\hline$Q$ & 86.20 & 1207.04 & 3.81 & 32.76 & 1.04 \\
\hline$R$ & 150.10 & 1010.65 & 5.99 & 37.64 & 1.40 \\
\hline
\end{tabular}

Source: Self-Authorship

In addition to the samples above, 9 extra samples were prepared by mixing two organic-mineral fertilizers ( $\mathrm{A}$ and $\mathrm{B}$ ) at various concentrations to obtain a range of $\mathrm{K}$ concentration between $200 \mathrm{mg} / \mathrm{kg}$ and $500 \mathrm{mg} / \mathrm{kg}$. Within the range of $200 \mathrm{mg} / \mathrm{kg}$ and 500 $\mathrm{mg} / \mathrm{kg}$ there were no samples containing this concentration in terms of $\mathrm{K}$, thus a satisfactory calibration curve could not be built. After the addition of these extra samples, a satisfactory calibration curve was built for $\mathrm{K}$.

\subsection{Spectral baseline correction}

The spectral baseline correction was done in a two-step process. First, a LIBS laser shot was taken with no sample present and this produced a clear spectral graph that had no influence from the samples, this was followed by taking a spectral graph generated by a LIBS shot on a fertilizer sample. Blank spectra were used because they produce the same plasma fluctuations that fertilizer samples do and this allows for the blank spectra to be used as reference points for minimizing the fluctuations on the fertilizer samples. The purpose of this 
was to correct the electronic offset, which helps avoid possible deviations from sample to sample. Second, the further offset caused by the continuum plasma emission was also corrected. This step, required that a line be set under the atomic emission peak, which passed through 4-5 points from end to end of the peak with no interference of any other emission peak (Fig. 15a). Following the fitting of the line under the emission peak, the peak was then subtracted from the spectrum from end to end within the designated points of interest. To extract the information of the peak, an asymmetrical Lorentzian function was fitted to the isolated peak of each spectrum (Fig. 15b).$^{38}$

Figure 15 - a.) Fitted line under peak to designate region of interest and b.) Lorentzian asymmetrical fit to extract area of the corrected peak
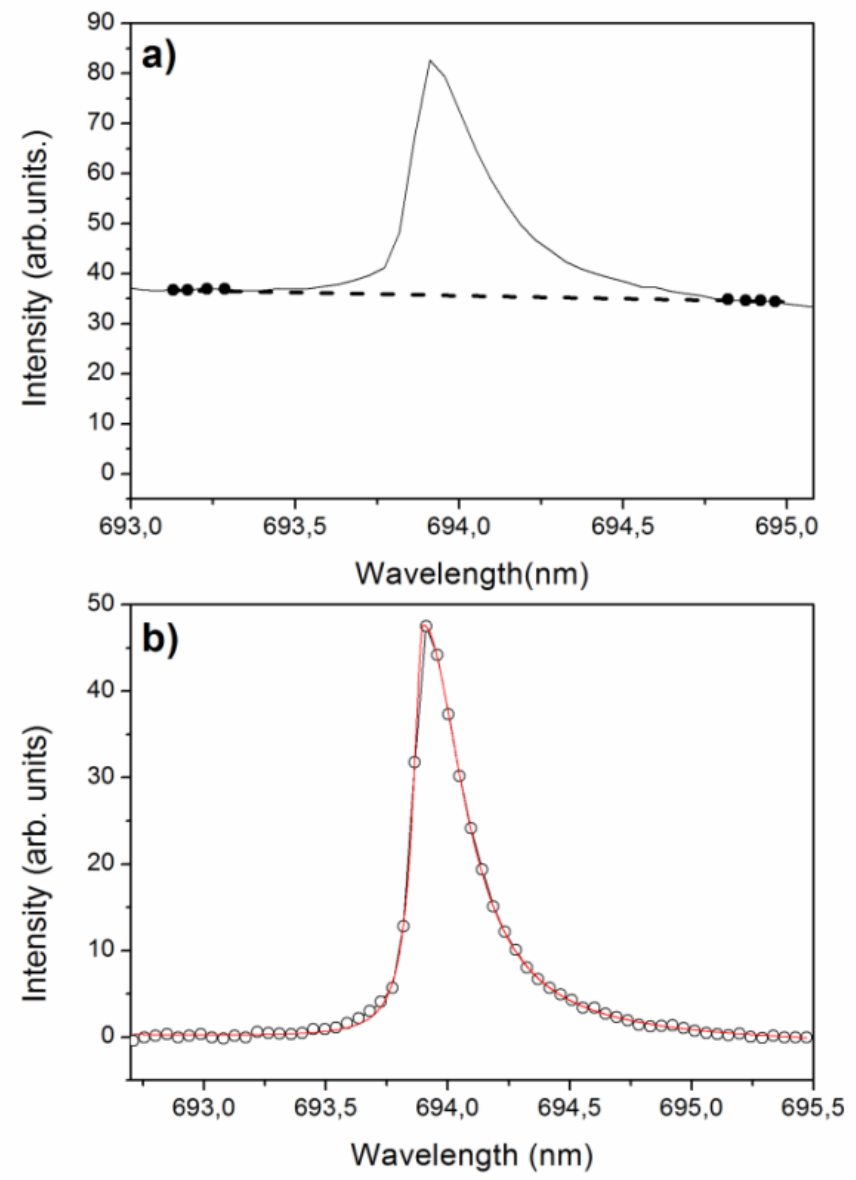

Source: Self-Authorship

\subsection{Area Normalization}

Moreover, after the spectral correction had been done and the area of the corrected peak $\left(\mathrm{A}_{\mathrm{I}}\right)$ was extracted, the area under this peak was also calculated $\left(\mathrm{A}_{\mathrm{II}}\right)$. Amongst $\mathrm{A}_{\mathrm{I}}$ and $A_{I I}$ the area was normalized $\left(A_{f}=A_{I} / A_{I I}\right)$ (Fig. 16). The final area $\left(A_{f}\right)$ is what was used to 
build the calibration models with FAAS. This normalization process was done to help with the correction of the matrix effects and as mentioned there were three different main types of samples, thus the influence of the matrix effects on plasma fluctuation varied amongst the samples. The procedure itself was used as an internal standard capable of maintaining the signal intensity proportional to the element concentration, thus helping to overcome the difference between the sample matrices. The normalization process corrected small laser power fluctuations and small misalignments; this is essential for portable systems to overcome in field measurements. Assuming that the stoichiometry between samples and plasma was maintained and only the plasma volume changed, the continuum plasma emission could be expected to change in the same proportion as the peak emission. Based on this argument, the area of the peak transition was normalized by taking into consideration the continuum plasma emission area below the peak. ${ }^{21}$

Figure 16 - Area normalization procedure

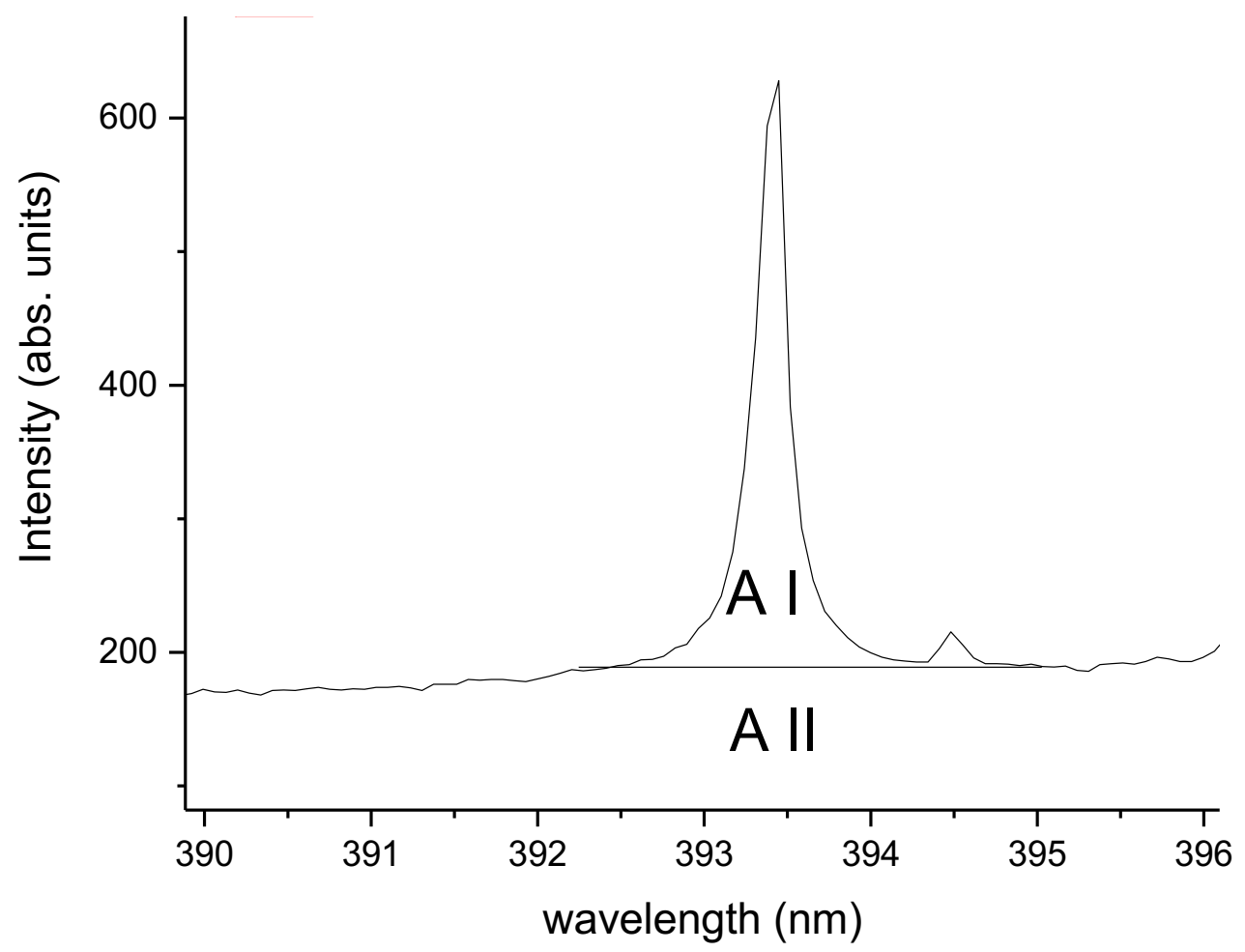

Source: Self-Authorship 


\subsection{Correlation Analysis for Line Emission Selection}

The best emission peak of the spectrum for each element was chosen based on the comparison of FAAS reference data with the spectral pixels. This was done to build calibration models with the best representative peaks for each element of interest. The first step in this process required the elimination of outlier spectra and this was done by the spectral angle mapper technique (SAM), which was applied through MatLab . ${ }^{39}$ The "SAM" method eliminates outlier spectra by comparing two spectra and returning a scalar value between -1 and 1, based on their similarity. After outlier spectra were removed, the average of all the spectra were taken for each sample. Specific points in the spectra representing the elements of interest were then chosen to compare them to the FAAS reference data. The chosen points were cross-referenced with information provided by the NIST website. ${ }^{40}$ Once the wavelength points were chosen, a Pearson correlation analysis was done to find the most reliable peak for the calibration models. Emission peaks chosen for all elements were based on adequate " $\mathrm{R}$ " values. It was made sure through the use of the NIST database that no other elements interfered with the regions of interest and to make sure of this, a correlation analysis was performed with elements that appeared to be near the regions of interest. As an example, Figure 17 is shown and it represents the element $\mathrm{K}$. The reason this part of the analysis is necessary, is because as one can see below, the peak with the highest correlation is $769.9 \mathrm{~nm}$, however, it is auto-absorbed due to reasons outside the scope of knowledge required for this study, and when a normalization of the peak is applied to this emission line, the results are so unacceptable, that an example was not shown because it was significantly faulty. 
Figure 17 - Pearson correlation analysis between pixel intensity representing $\mathrm{K}$ and reference data from FAAS

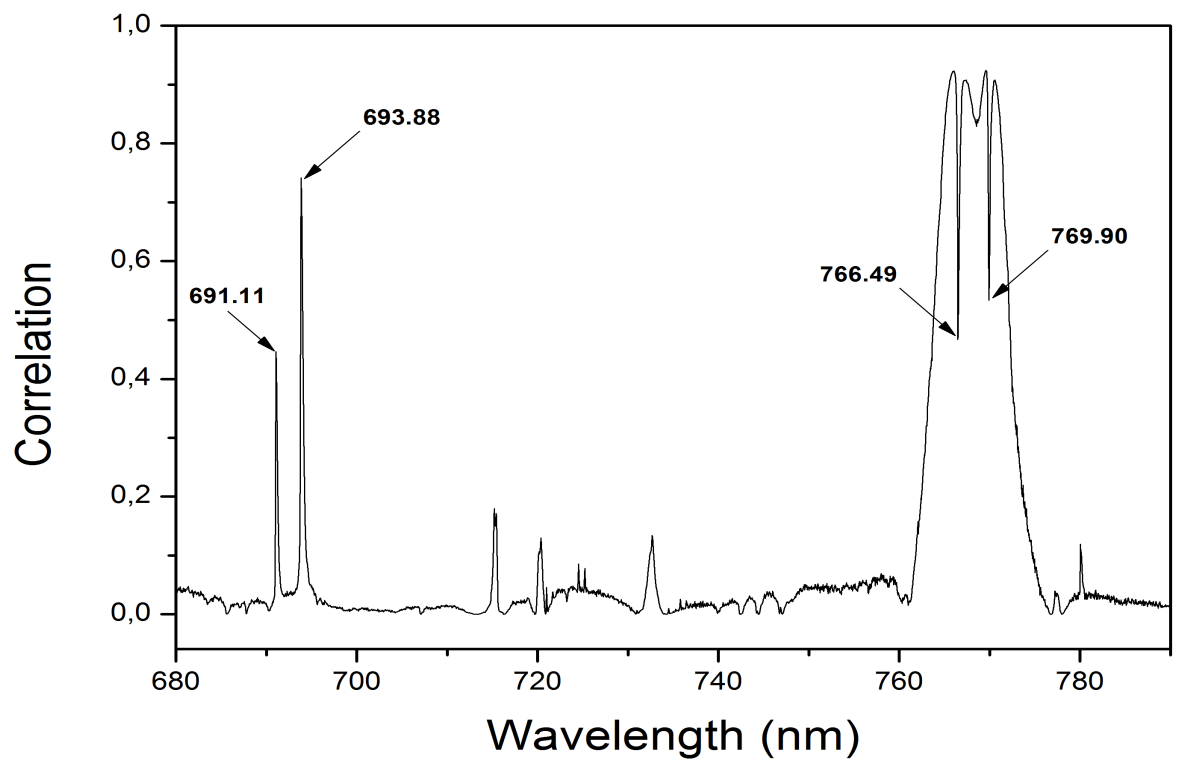

Source: Self-Authorship 


\section{RESULTS AND DISCUSSION}

\subsection{LIBS Plasma Temperature and Electron Density}

These two results were shown under the same section because they are relative to each other and one influences the other. The plasma temperature helps to confirm Local Thermal Equilibrium conditions (LTE) by satisfying other conditions involving the electron density. The condition of LTE is considered important for attaining reliable quantitative information because it means that the plasma holds a single temperature and it is not varying during analysis. To be in local thermodynamic equilibrium, the McWhirter criterion must be satisfied. The criterion is essentially the satisfaction of the condition Ne (electron density) $\geq$ $1.6 \times 10^{12} \Delta \mathrm{E}^{3} \mathrm{~T}^{1 / 2}$, where " $\Delta \mathrm{E}$ " $(\mathrm{eV})$ is the largest transition energy for which the condition holds and " $\mathrm{T}$ " is the plasma temperature. ${ }^{41}$

In addition, it is important to have precision in the analysis of these results and other results, such as the calibration curves that will be shown, so that the precision of the instrument can be credible. Figure 18 from a previously published paper by our group is presented here to demonstrate that the LIBS system used can indeed be consistent with all the results that will be presented. A reference sample of known concentration was used and was analyzed for its concentration of Phosphorus (P) by LIBS for 150 days in 30-day intervals. The results showed that the error was within $10 \%$, thus confirming that the LIBS system could be repeatable.

Figure 18 - 150 day measurement of Phosphorus (P) sample

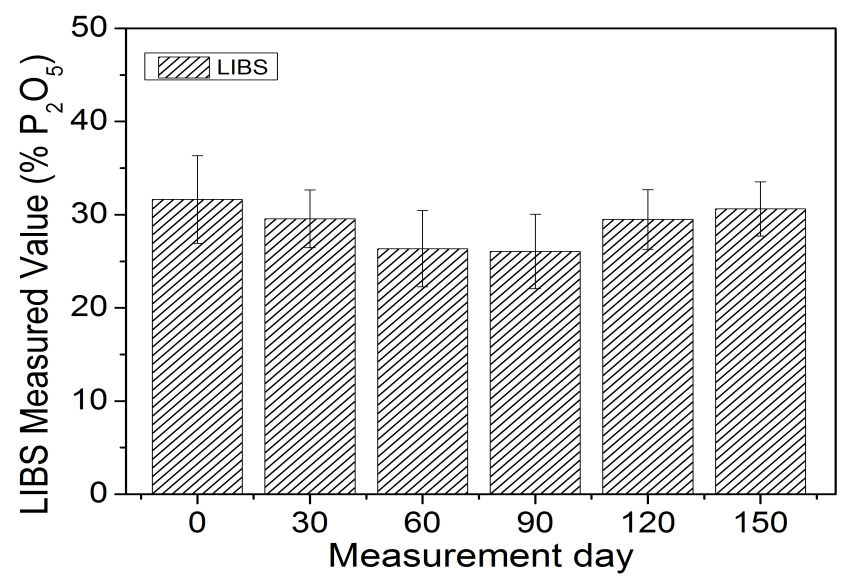

Source: Marangoni, B. S., 2016, p. 81 License \# 4007731044844 


\subsubsection{LIBS Plasma Temperature}

The plasma temperature was calculated through a Boltzmann plot developed using the element $\mathrm{Ca}$, since it has various lines present in the spectra. For each sample, " $\ln \left(\mathrm{I} \lambda / \mathrm{g}_{\mathrm{ki}} \mathrm{A}\right)$ " was plotted against " $\mathrm{E}_{\mathrm{u}}$ " (in eV) to illustrate the Boltzmann plot. "I2 "I" is the LIBS intensity produced by the elements of interest; however, it can be influenced by the plasma due to differences in fluctuations caused by the different matrices of the fertilizer samples used. The normalized area extracted from the peaks of interest was used instead of the direct LIBS intensity produced by the raw spectra; this was done to avoid inconsistencies in the results. " $\lambda$ " is the wavelength of the elements used, " $\mathrm{g}_{\mathrm{ki}}$ " and " $\mathrm{A}$ " are known as the degeneracy and transition probability, which are values that can be attained from the NIST database. ${ }^{40}$ Five Ca spectral lines were used $(443.5 \mathrm{~nm}, 610.2 \mathrm{~nm}, 643.9 \mathrm{~nm}, 428.3 \mathrm{~nm}, 585.7 \mathrm{~nm})$ and a straight-line plot was fitted to produce the Boltzmann plot (Fig. 19). The slope of the line from the Boltzmann plot is equal to "-1/kT", with " $\mathrm{k}$ " being the Boltzmann constant $\left(8.6173324(78) \times 10^{-5} \mathrm{eV} / \mathrm{K}\right)$ and " $\mathrm{T}$ " the temperature of the plasma, which is normally reported in Kelvin (K) units. 3 samples, one from each of the 3 main groups of fertilizers was used to calculate the plasma temperature: Dejebel (Phosphate rock), Map (Commercial mineral), and Sample C (Organomineral).

Figure 19 - Boltzmann Plot using Ca

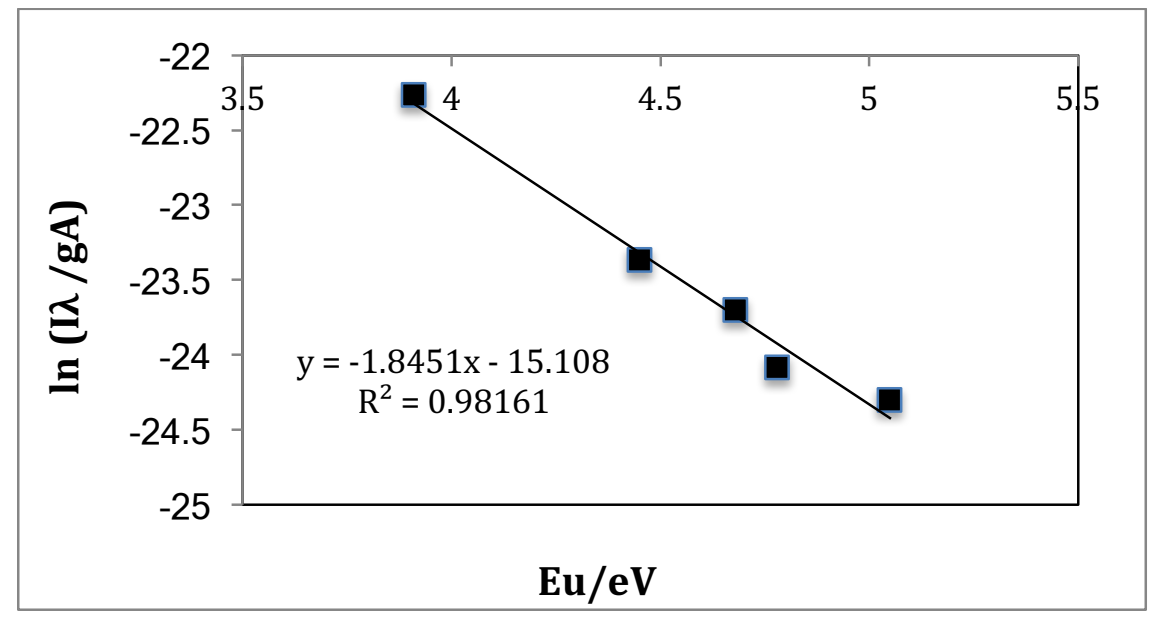

Source: Self-Authorship

Table 2 shows the plasma temperatures calculated and they are somewhat consistent, yielding a mean temperature of $6813 \mathrm{~K}$. The ability to calculate the temperature consistently 
can be attributed to the normalization procedure applied because one of the main things influencing the intensity of the LIBS emission signal, is plasma fluctuation (volume changes), however, since the normalization procedure corrected for factors such as fluctuation, a Boltzmann plot producing satisfactory temperatures was possible.

Table 2 - LIBS Plasma Temperatures

\begin{tabular}{|c|c|}
\hline Fertilizer & Avg. Temp (K) \\
\hline Djebel & 6860 \\
\hline MAP & 6290 \\
\hline Organomineral C & 7290 \\
\hline Mean Temp. & 6813 \\
\hline
\end{tabular}

Source: Self-Authorship

\subsubsection{LIBS Plasma Electron Density}

The electron density $(\mathrm{Ne})$ of the plasma is dependent upon the width of starkbroadened lines and two types of stark effects exist on lines present in the plasma: quadratic and linear stark effects. Only the hydrogen atom exhibits the linear stark effect, thus making it easier to calculate the full-width at half-maximum intensity (FWHM) with greater accuracy, whereas other atoms exhibit the quadratic start effect. The electron density was calculated by using the equation " $\mathrm{Ne}=8.02 \times 10^{12}\left[\Delta \lambda_{1 / 2} / \alpha_{1 / 2}\right]^{3 / 2}$ ", where " $\Delta \lambda_{1 / 2}$ " is the FWHM of the hydrogen line at $656.5 \mathrm{~nm}$ (Fig. 20) and " $\alpha_{1 / 2}$ " is the reduced wavelength. ${ }^{41}$ The reduced wavelength values were estimated by using values attained from Griem's 1974 appendix. In Griem's appendix, they only give the reduced wavelength at specific temperatures and for this process we took values close to our estimated plasma temperature and built a graph that allowed us to extrapolate the reduced wavelength value at $6813 \mathrm{~K} .{ }^{43}$ 
Figure 20 - FWHM of Hydrogen line $656.6 \mathrm{~nm}$

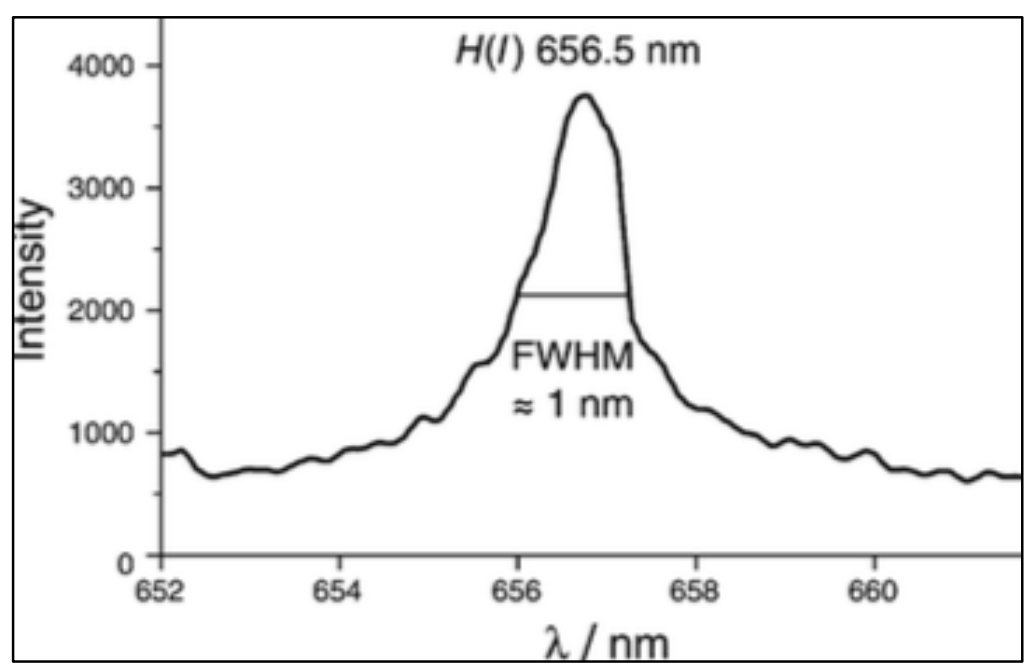

Source: Najarian, M. L., 2012, p. 246

Table 3 shows the results from the calculated electron density and as discussed earlier, to ensure LTE conditions the McWhirter criterion must be satisfied, which is $\mathrm{Ne} \geq 1.6 \times 10^{12}$ $\Delta \mathrm{E}^{3} \mathrm{~T}^{1 / 2}$. The column in the middle of Table 3 shows the average electron density belonging to each of the three samples representing the different matrices and the column on the far right shows the values that must be smaller or equal to the electron density for McWhirter criterion to be satisfied. As one can see, the criterion was satisfied, thus we can say that our analysis was at least close or in LTE conditions and quantitative information produced can be reliable.

Table 3 - LIBS Plasma Electron Density and LTE conditions

\begin{tabular}{|c|c|c|}
\hline Fertilizer & Average $\mathrm{Ne}\left(\mathrm{cm}^{-3}\right)$ & $\begin{array}{c}=1.6 \times 10^{12} \Delta E^{3} T^{1 / 2} \\
\left(\mathrm{~cm}^{-3}\right)\end{array}$ \\
\hline Djebel & $1.46 \times 10^{16}$ & $1.11 \times 10^{15}$ \\
\hline$M A P$ & $1.61 \times 10^{16}$ & $1.06 \times 10^{15}$ \\
\hline Organomineral C & $9.63 \times 10^{15}$ & $1.14 \times 10^{15}$ \\
\hline
\end{tabular}

Source: Self-Authorship 


\subsection{Emission lines}

The LIBS emission lines were chosen from a raw spectra graph representing the different samples, such as the one shown in Figure 21, which is the spectrum from the sample Djebel. The best emission lines that represented the elements when comparing them to FAAS were chosen. The emission lines chosen are shown in Figures 21-26 and a summary of them is shown in Table 4.

Figure 21 - Spectra graph of the Djebel sample

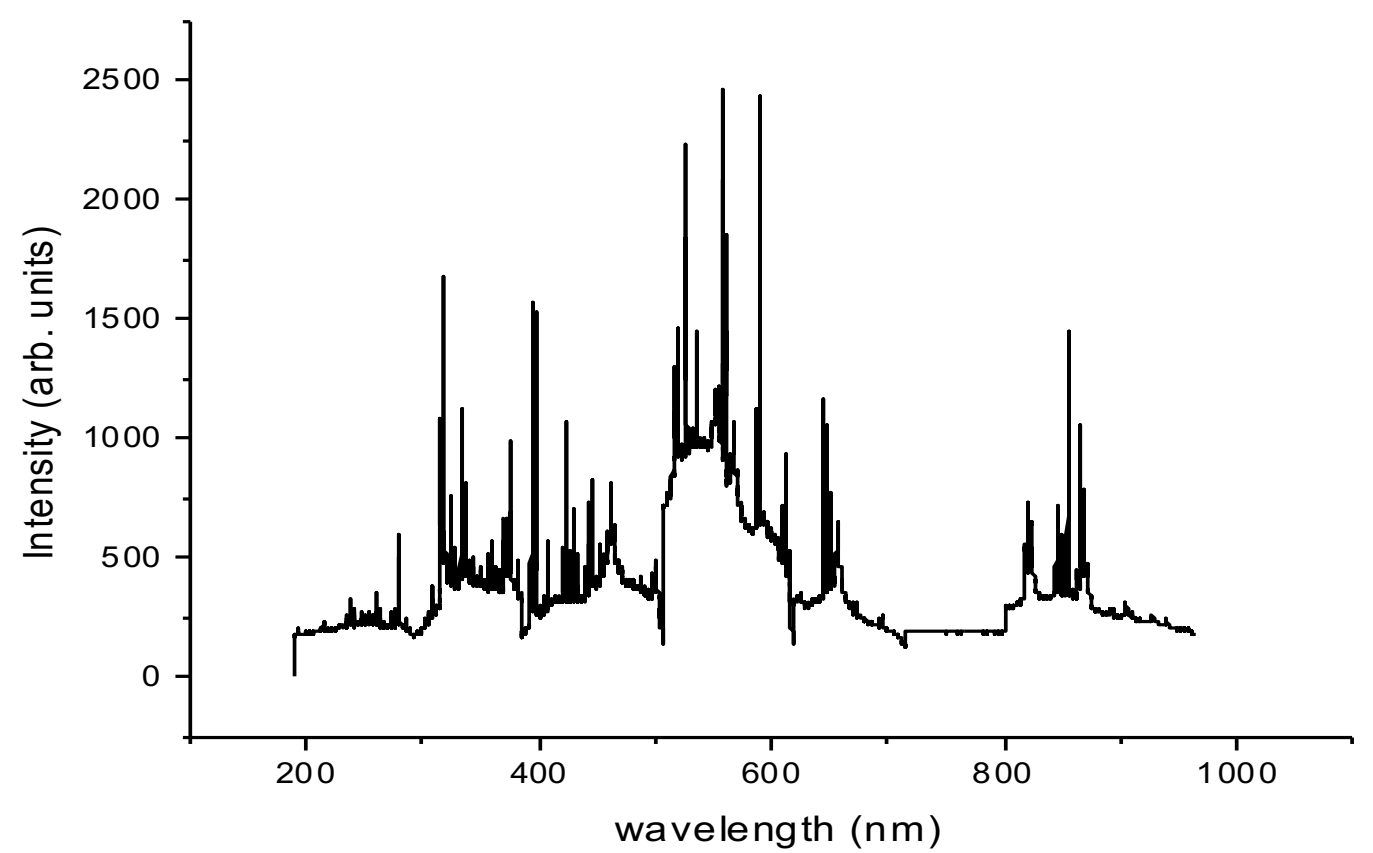

Source: Self-Authorship

Figure 22 shows the emission line chosen for the element K I at $693.88 \mathrm{~nm}$. When evaluating this element, it was noticed that there was an auto-absorption of the peak at $769.90 \mathrm{~nm}$ as can be seen in Figure 17, which is a peak that was better representative of K. However, the second best peak at $693.88 \mathrm{~nm}$ was chosen and great results were achieved when calibration curves were built using the data from the reference technique. 
Figure 22 - K I emission line 693.88nm

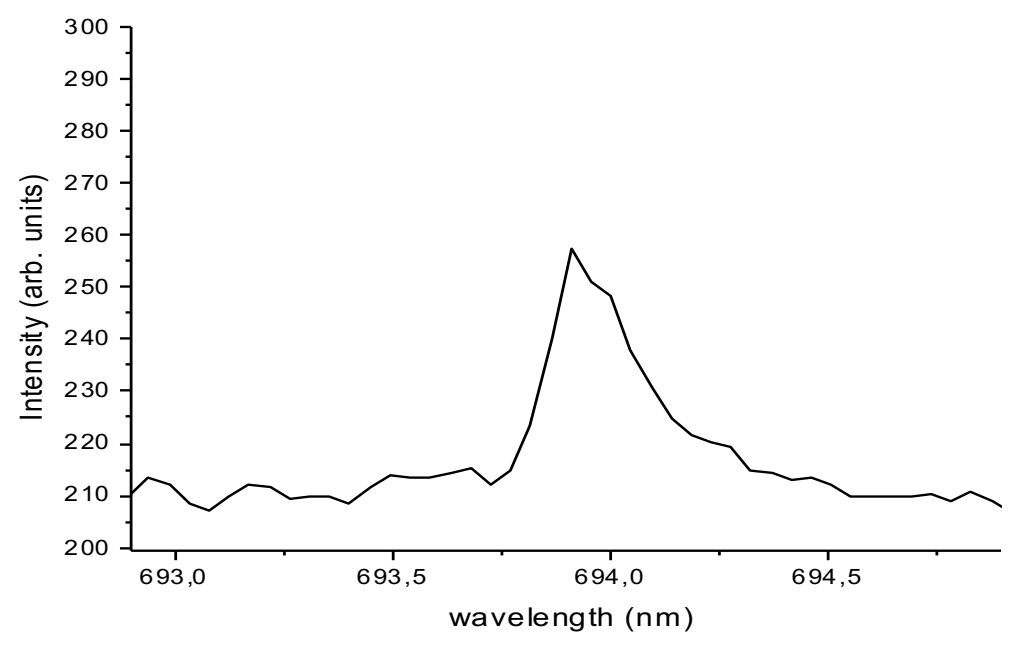

Source: Self-Authorship

Figure 23 shows the emission line chosen for the element $\mathrm{Ca}$. Finding which emission line best fits the data when compared to the reference techniques for Ca was the easiest of all the emission lines chosen because the element $\mathrm{Ca}$ has many emission lines that have strong and clear signals. The emission lines $610.27 \mathrm{~nm}, \quad 443.50 \mathrm{~nm}, \quad 643.90 \mathrm{~nm}, \quad 428.30 \mathrm{~nm}, \quad$ and $585.700 \mathrm{~nm}$ were all worthy candidates, but $\mathrm{Ca}$ I $610.27 \mathrm{~nm}$ was used because it was the clearest of them all by a slight margin.

Figure 23 - Ca I emission line $610.27 \mathrm{~nm}$

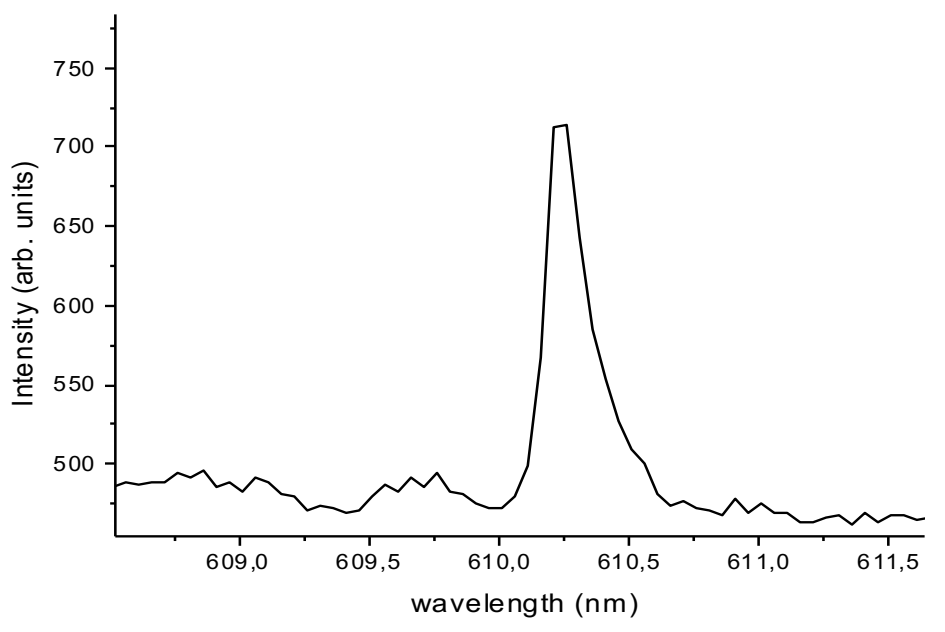

Source: Self-Authorship 
Figure 24 shows the emission line for the element Mn at 256.30nm. For this particular element, the Mn II transition line was chosen because the atomic emission lines were not worthy of producing adequate calibration curves.

Figure 24 - Mn II emission line 256.3nm

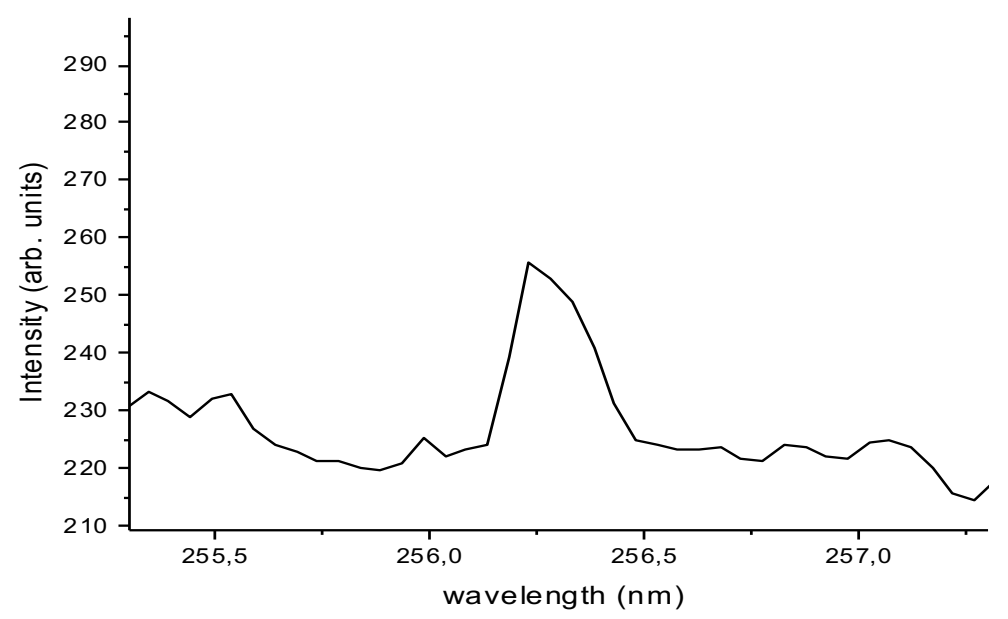

Source: Self-Authorship

Figure 25 shows the emission line for the element $\mathrm{Mg}$ I at 285.20nm. In other LIBS experiments, it was noticed that this emission line was a common one that was chosen to build calibration curves, thus we chose it as well and when calibration curves were built using this emission line, acceptable results were achieved.

Figure 25 - Mg I emission line 285.2nm

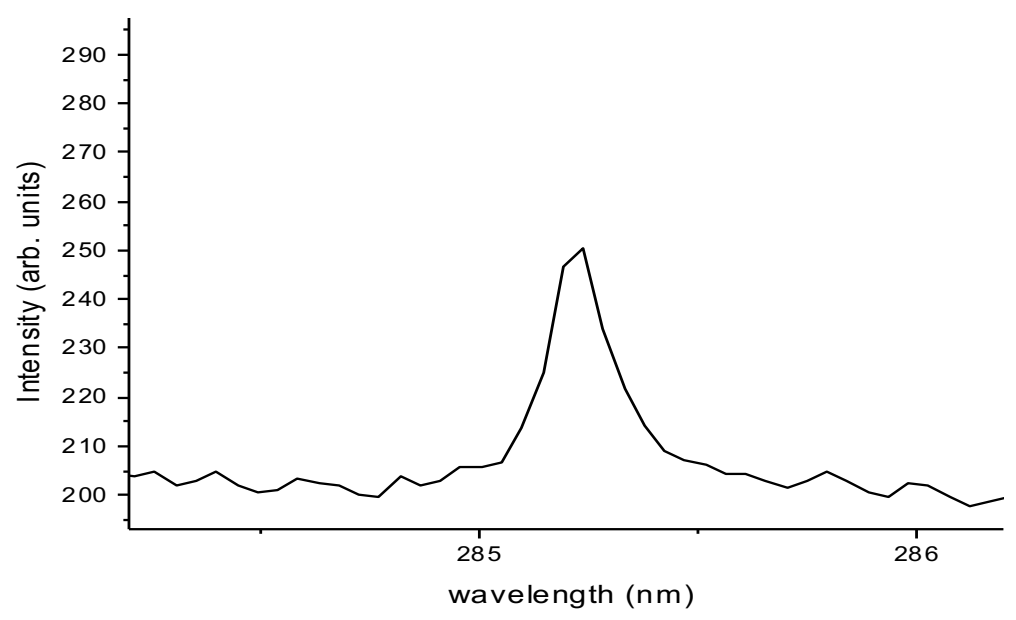

Source: Self-Authorship 
Figure 26 shows the emission line for element $\mathrm{Cu}$ I at $280.25 \mathrm{~nm}$. This emission line was the most difficult to determine because of the elements low concentration in our samples, which means that its emission signal was not very strong. Although the element was detected clearly on the spectra, the single pulse LIBS system is not a strongly-established technique for quantification, thus if the signal is weak or interfered with by an element with a similar wavelength the result can be skewed. The emission signal is best when it is strong and clear, so that good results can be achieved when building calibration curves. The emission line chosen experienced a bit of interference from a neighboring element and it required careful designation of the regions of interest for extraction of the area using the normalization procedure. Moreover, the emission line for $\mathrm{Cu}$ could produce acceptable results on the calibration curves despite the very low concentration of the element and the weak signal produced by the LIBS system. If the emission line were stronger and clearer, the signal would have produced better results on the calibration curves.

Figure 26 - Cu I emission line $280.25 \mathrm{~nm}$

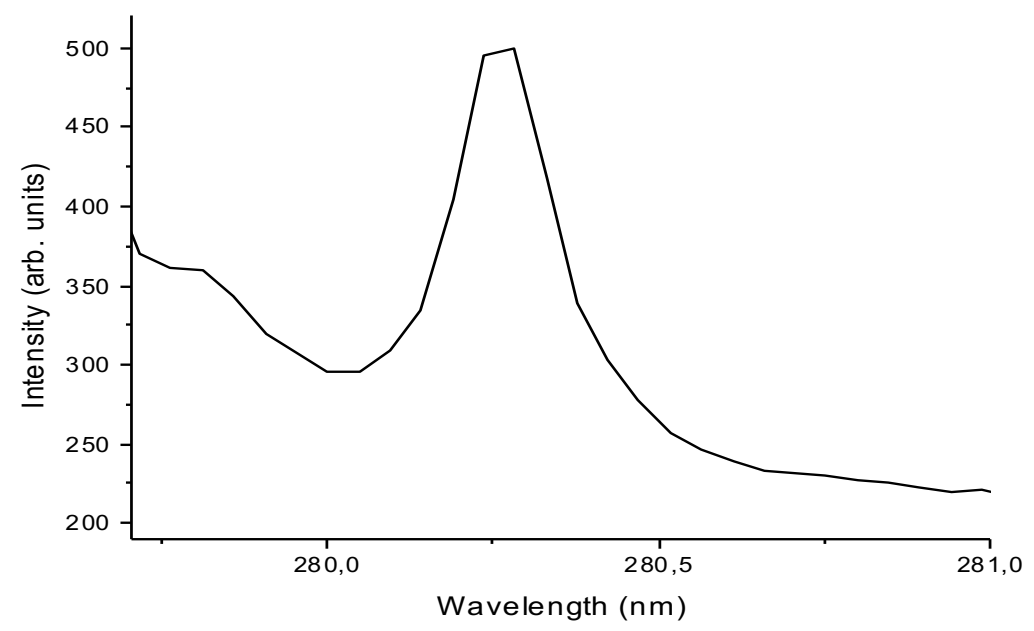

Source: Self-Authorship 
Table 4 - Summary of emission lines chosen

\begin{tabular}{|c|c|}
\hline Elements & LIBS Emission Line (nm) \\
\hline $\mathrm{K} \mathrm{I}$ & 693.88 \\
\hline $\mathrm{Ca} \mathrm{I}$ & 610.27 \\
\hline $\mathrm{Mn} \mathrm{II}$ & 256.30 \\
\hline $\mathrm{Mg} \mathrm{I}$ & 285.20 \\
\hline $\mathrm{Cu} \mathrm{I}$ & 280.25 \\
\hline
\end{tabular}

Source: Self-Authorship

\subsection{Linear Fits for LIBS and reference technique FAAS}

Calibrations curves for $\mathrm{K}, \mathrm{Ca}, \mathrm{Mn}, \mathrm{Mg}$, and $\mathrm{Cu}$ were built using the LIBS normalized area and the FAAS data $(\mathrm{mg} / \mathrm{kg})$ as the reference technique. The results obtained by LIBS using FAAS as the reference technique were considered adequate. For these models, there were situations where not using the normalized area caused a decrease of 0.1-0.2 points on the R correlation value. The LOD was also calculated for LIBS relative to the FAAS technique and results obtained there, were also adequate. Figures 27-31 show the calibrations curves for LIBS-FAAS and Table 5 is a summary of the results.

\subsubsection{LIBS and FAAS calibration curves}

Figure 27 shows the calibration curve for the element K, which yielded good results. A correlation value of 0.97 raises the credibility of the LIBS system in its ability to quantify the element $\mathrm{K}$ in fertilizers of different matrices. When the LIBS area was not normalized, the correlation value dropped to 0.81 . The estimated LIBS LOD relative to the FAAS model was calculated to be $660 \mathrm{mg} / \mathrm{kg}$. 
Figure 27 - Calibration model for K between LIBS and FAAS

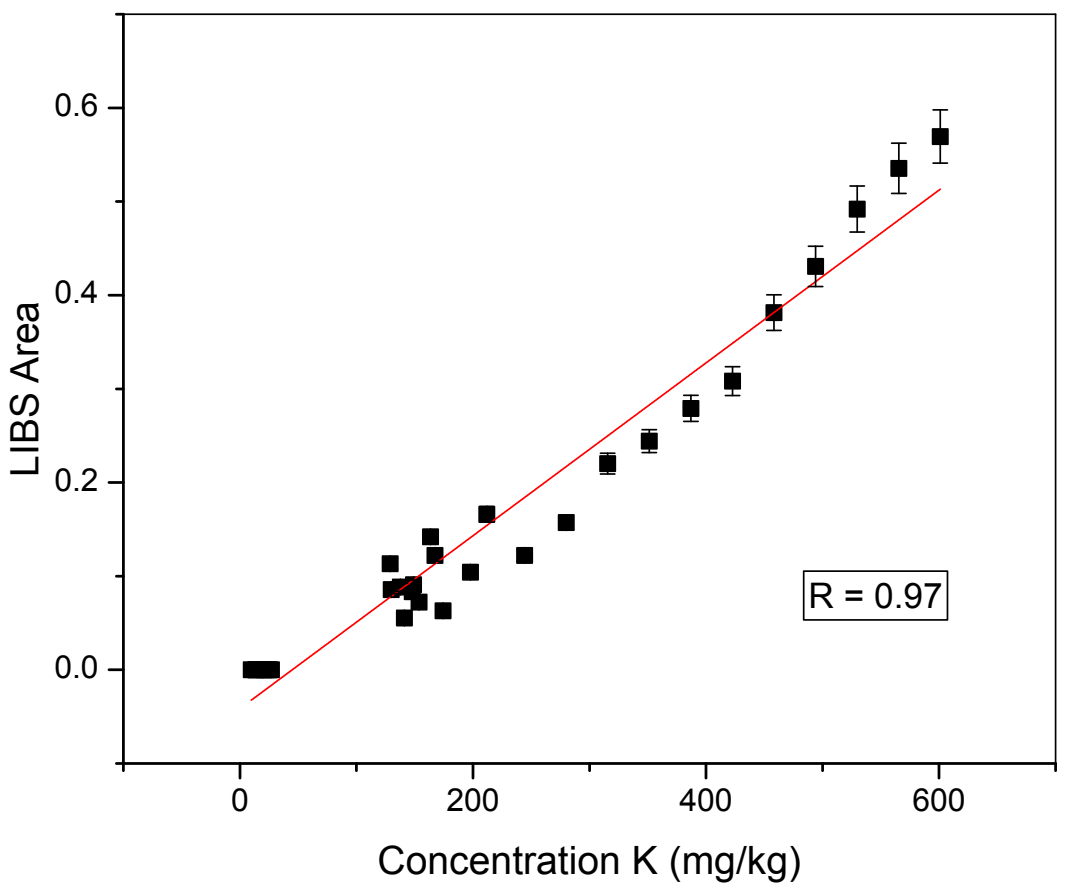

Source: Self-Authorship

Figure 28 shows the LIBS-FAAS calibration curve for the element $\mathrm{Ca}$. The correlation value of 0.96 was a good result and confirms the ability of LIBS to quantify this element in fertilizer. The estimated LIBS LOD was calculated to be $350 \mathrm{mg} / \mathrm{kg}$ which was a value in which all samples fell within range, except for one (MAP).

Figure 28 - Calibration model for Ca between LIBS and FAAS

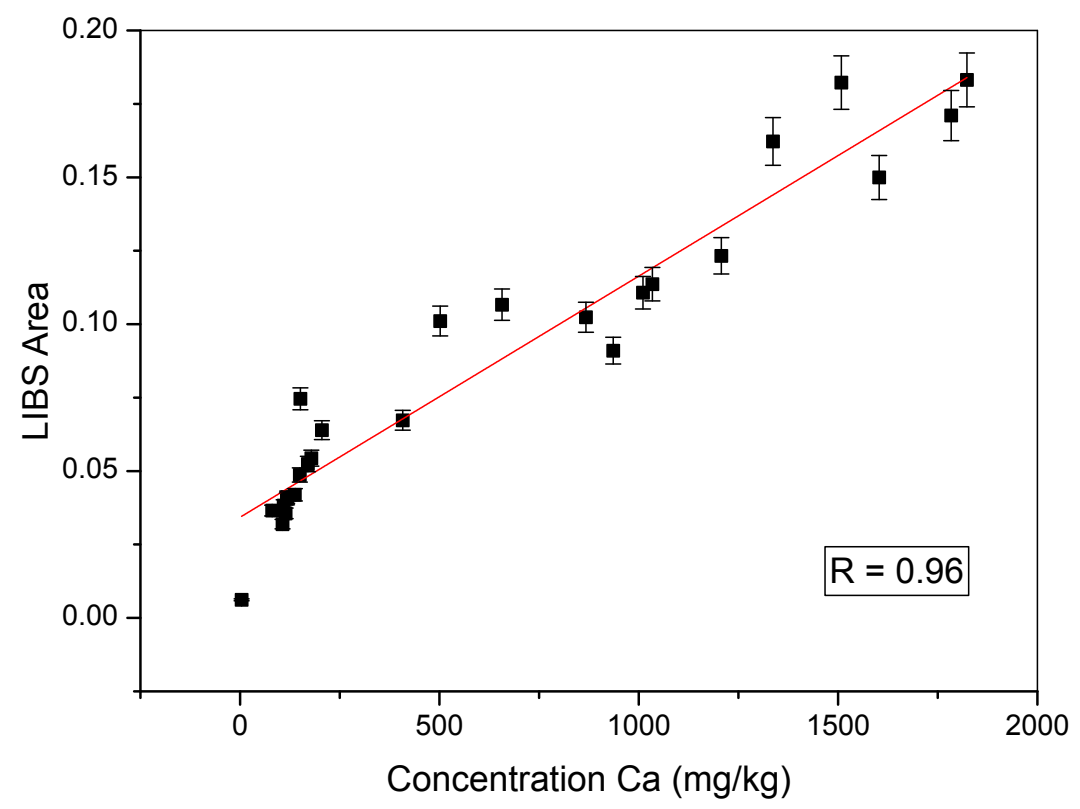

Source: Self-Authorship 
Figure 29 shows the calibration model for the element Mn. The results were also considered adequate. The correlation value is 0.84 and the estimated LIBS LOD value is 8 $\mathrm{mg} / \mathrm{kg}$.

Figure 29 - Calibration model for Mn between LIBS and FAAS

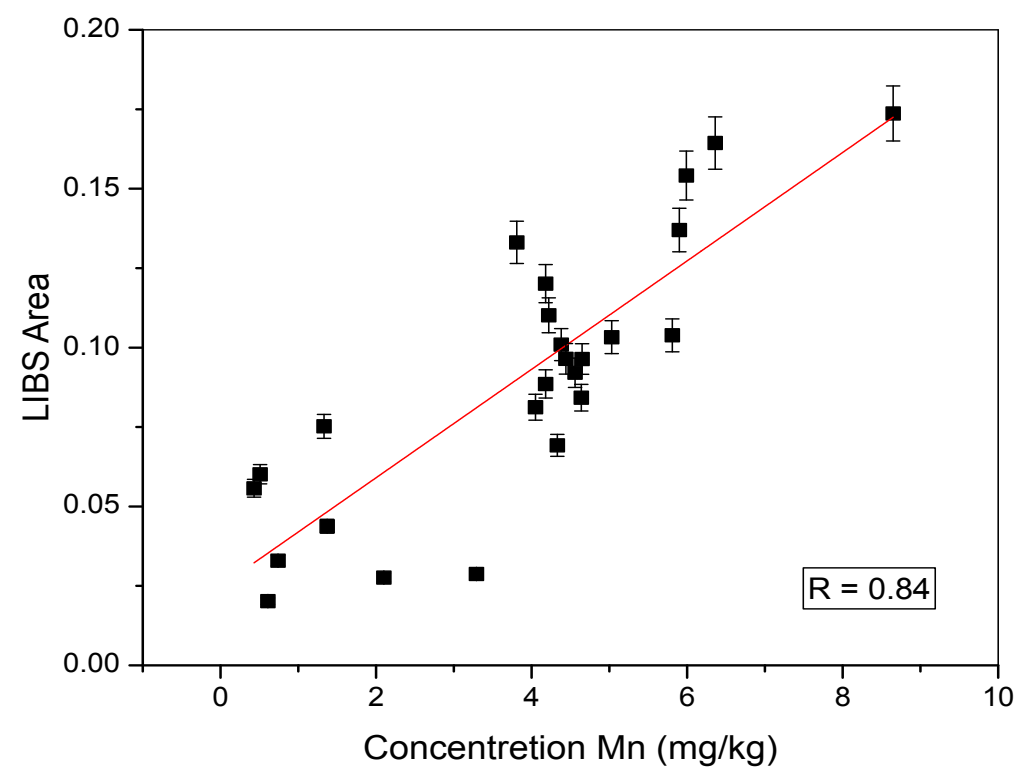

Source: Self-Authorship

Figure 30 shows the calibration curve for the element $\mathrm{Mg}$. The results were considered adequate at a correlation value of 0.86 . It is worth noting that when the normalization procedure was not applied to the LIBS area, the correlation value yielded was 0.63 . The estimated LIBS LOD value was calculated to be $54 \mathrm{mg} / \mathrm{kg}$. 
Figure 30 - Calibration model for Mg between LIBS and FAAS



Source: Self-Authorship

Lastly, the calibration curve for the element $\mathrm{Cu}$ yielded good results as well, similar to the other models. The correlation value attained was 0.86 and the estimated LIBS LOD is 8.4 $\mathrm{mg} / \mathrm{kg}$.

Figure 31 - Calibration model for $\mathrm{Cu}$ between LIBS and FAAS

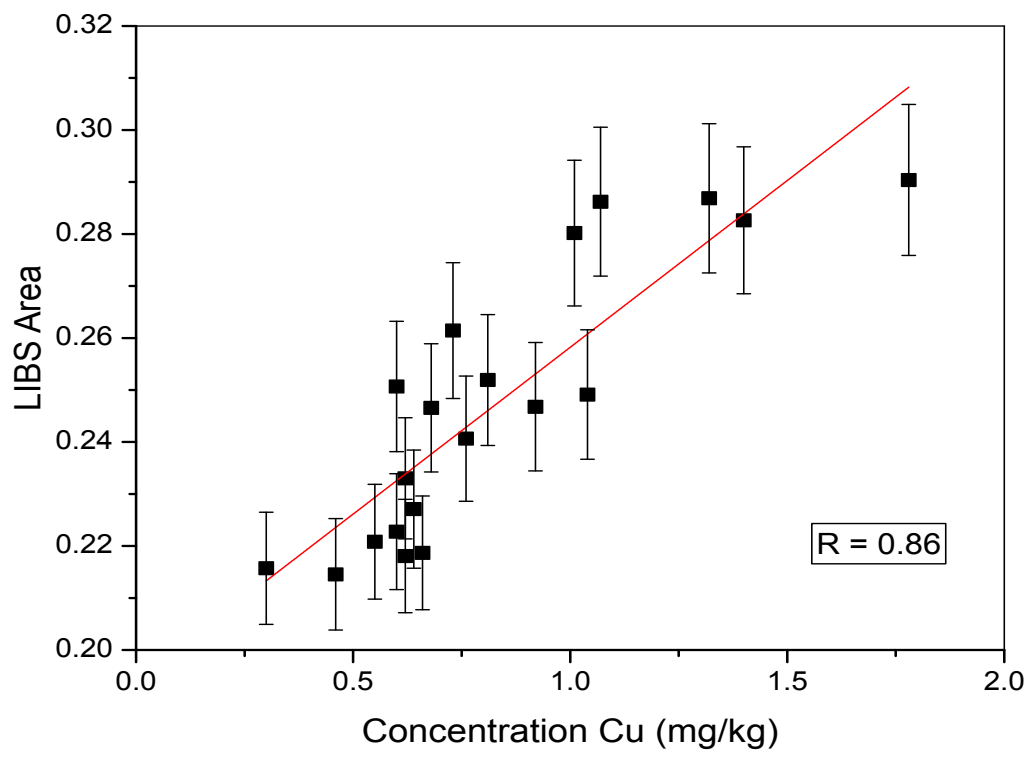

Source: Self-Authorship 
Table 5 shows the summary of the correlation results attained, the LOD, and the LOQ relative to the calibration models. The LOD results fall within a range much lower than that of concentrations that are usually present in fertilizers produced around the world. The LOQ is also within a good range that is less than concentrations usually present in fertilizers.

Table 5 - Summary of calibration curve results with LOD relative to LIBS-FAAS

\begin{tabular}{|c|c|c|c|}
\hline Elements & LIBS and FAAS (R) & $\begin{array}{c}\text { LIBS-FAAS LOD } \\
(\mathbf{m g} / \mathbf{k g})\end{array}$ & $\begin{array}{c}\text { LIBS-FAAS LOQ } \\
\mathbf{( m g} / \mathbf{k g})\end{array}$ \\
\hline $\mathrm{K}$ & 0.97 & 660 & 1,980 \\
\hline $\mathrm{Ca}$ & 0.96 & 350 & 1,050 \\
\hline $\mathrm{Mn}$ & 0.84 & 8 & 24 \\
\hline $\mathrm{Mg}$ & 0.86 & 54 & 162 \\
\hline $\mathrm{Cu}$ & 0.86 & 8.4 & 25.2 \\
\hline
\end{tabular}

Source: Self-Authorship

\subsection{Cross-Validation error analysis for LIBS and reference technique FAAS}

The leave one out cross-validation error analysis was also done. In this type of analysis, a sample is withdrawn from the calibration model, the calibration model without the sample is then used to test the removed sample and find what would be the predicted concentration using the normalized area. The predicted concentration is then compared with the FAAS concentration and an absolute error is found. A line is drawn at a $45^{\circ}$ angle going across the sample points to give a visual of the dispersion among the predicted values and the FAAS values, the more linear the relationship, the better the validation and the lower the average error. The analysis was done for every element and the results are reported in Figures 32-36 along with Table 6 showing the error values in a table format. For elements $\mathrm{K}, \mathrm{Cu}, \mathrm{Ca}$, and $\mathrm{Mn}$ high error values were produced $(22 \%-28 \%)$ at first, but when samples below the LOD were removed, the average cross-validation errors dropped significantly. For example, in element $\mathrm{K}$ an average error of $29.5 \%$ was produced, but when values below the LOD (690 $\mathrm{mg} / \mathrm{kg}$ ) were excluded from the analysis, the error dropped to $12 \%$. 


\subsubsection{LIBS and FAAS Cross-Validation analysis}

Figure 32 shows the cross-validation error analysis for the element $\mathrm{K}$. The average error produced amongst the samples was $12 \%$ which is relatively low. The good error result gives confidence to the LIBS instrument for the analysis of K.

Figure 32 - Cross-Validation error analysis for K between FAAS and LIBS Predicted Value

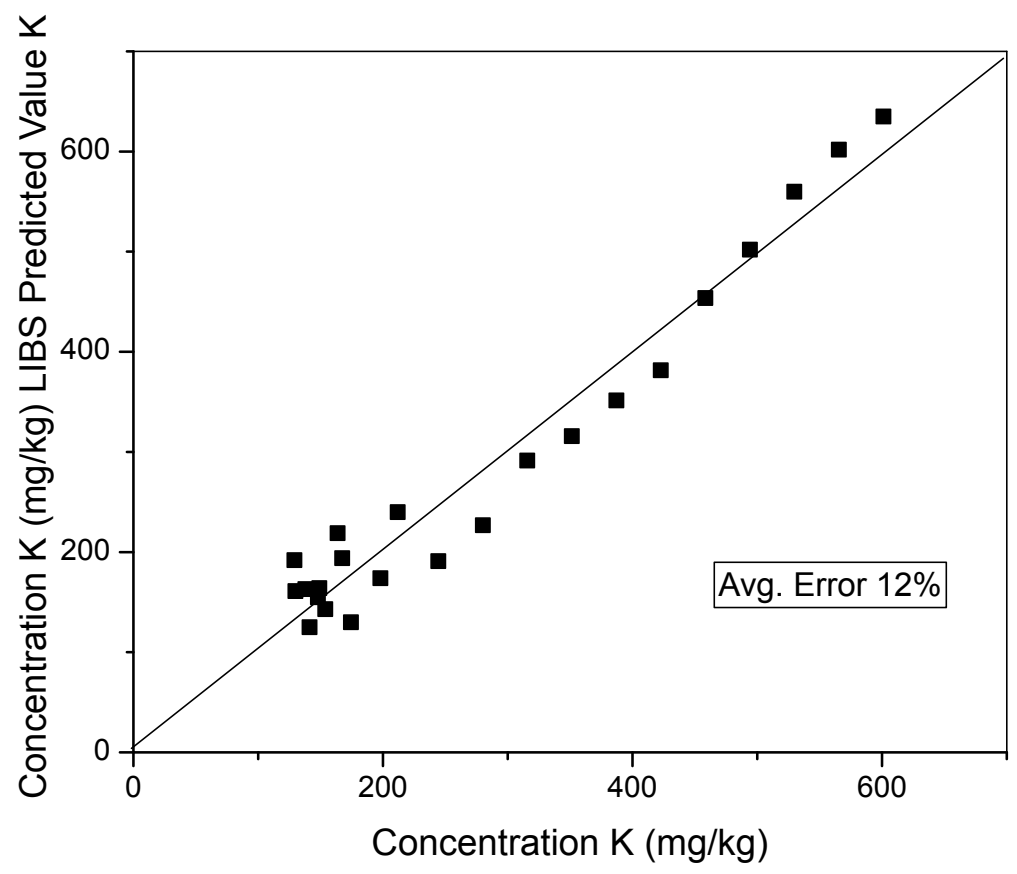

Source: Self-Authorship

Figure 33 shows the cross-validation error analysis for the element $\mathrm{Ca}$. The average error here was the largest of all the elements evaluated. The average error is $21 \%$ and the reason could be due to the high concentrations of $\mathrm{Ca}$ present in the samples. It was noticed across all the elements that samples above $500 \mathrm{mg} / \mathrm{kg}$, slightly exhibited non-linear behavior. The element $\mathrm{Ca}$ had concentrations above $500 \mathrm{mg} / \mathrm{kg}$ in many of the fertilizer samples. 
Figure 33 - Cross-Validation error analysis for Ca between FAAS and LIBS Predicted Value

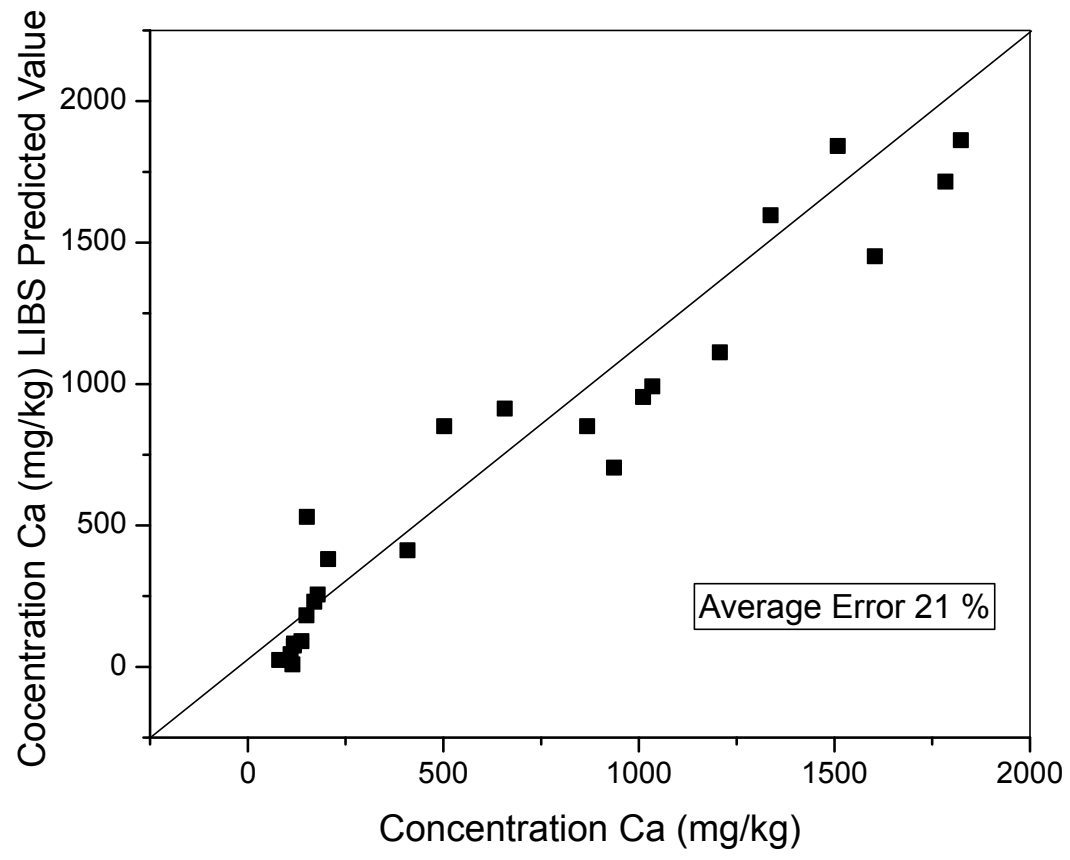

Source: Self-Authorship

Figure 34 shows the cross-validation error analysis for the element $\mathrm{Mn}$. The average error is $13 \%$, which is relatively good. Like the element $\mathrm{K}$, an error value around this range is considered adequate.

Figure 34 - Cross-Validation error analysis for Mn between FAAS and LIBS Predicted Value

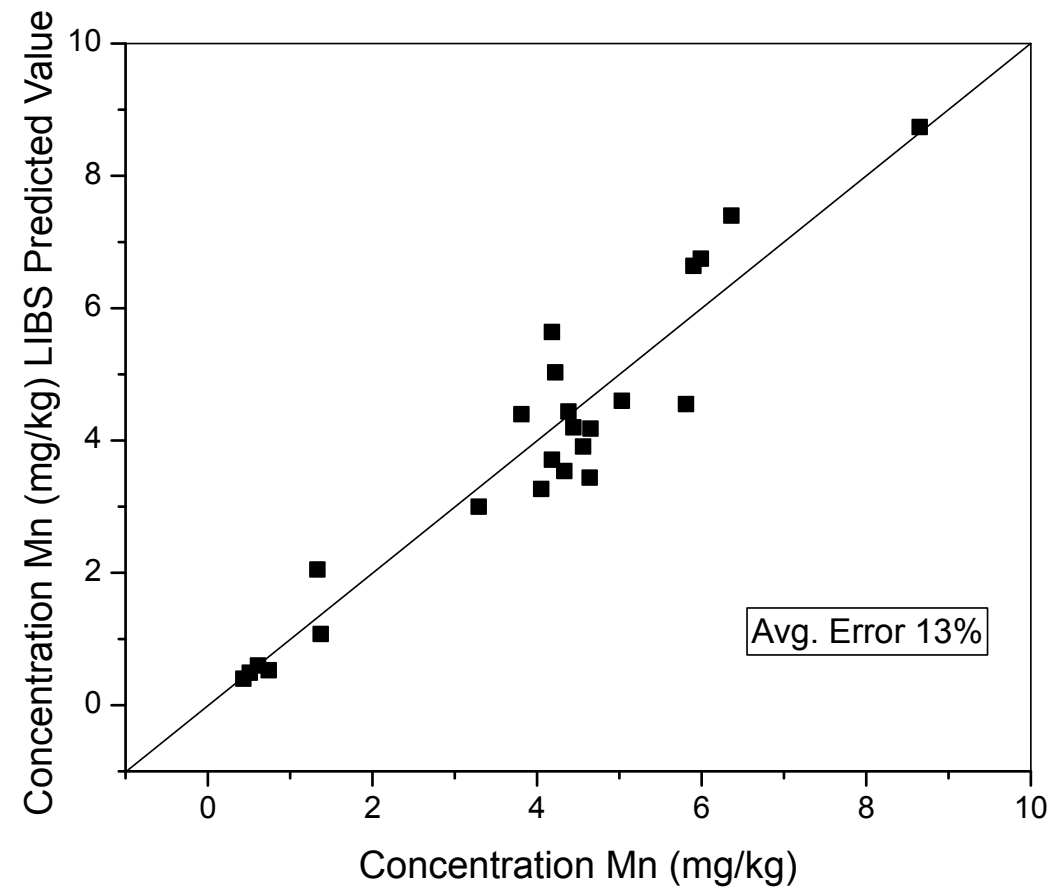

Source: Self-Authorship 
Figure 35 shows the cross-validation error analysis for the element $\mathrm{Mg}$. The average error is $8 \%$, which is good. This element yielded the lowest average error value of all the elements.

Figure 35 - Cross-Validation error analysis for Mg between FAAS and LIBS Predicted Value

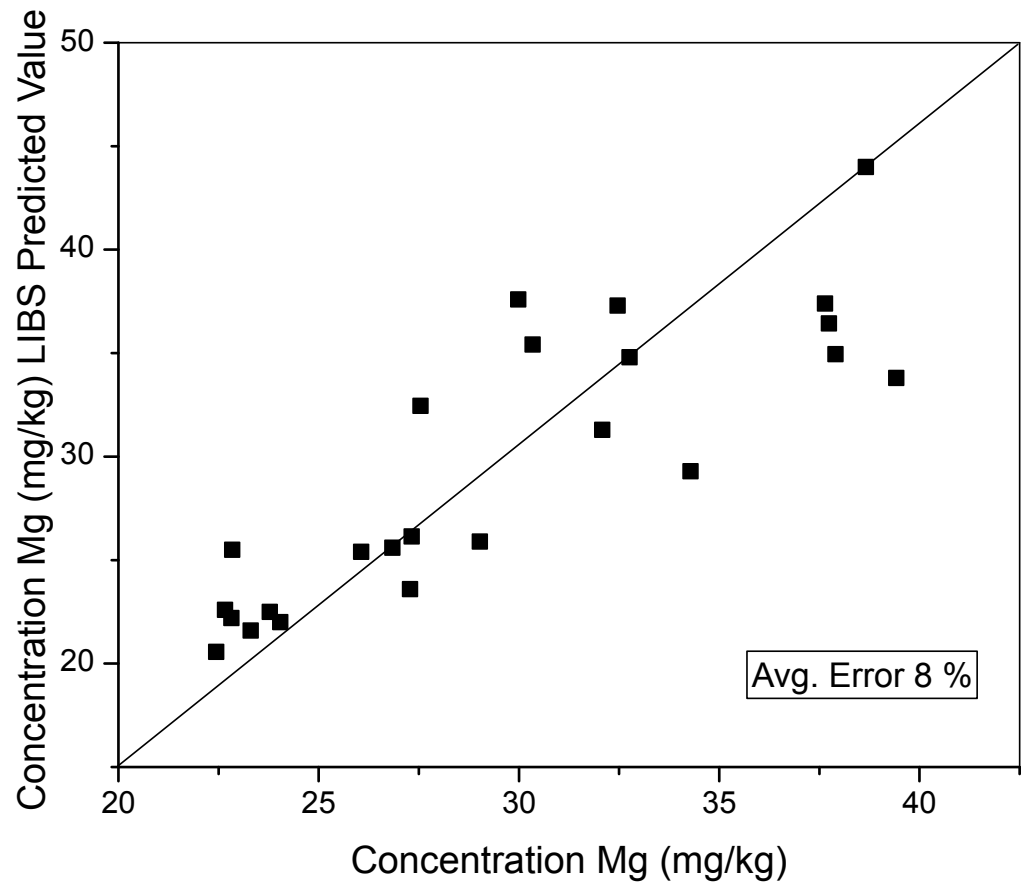

Source: Self-Authorship

Figure 36 shows the cross-validation error analysis for the element $\mathrm{Cu}$. The average error is $18 \%$, which is acceptable. The possibility as to why it is higher than the other elements is because of the same reason as $\mathrm{Ca}$ (non-linear behavior), except in this case it is due to concentrations being real low. When the concentration of the element is real low, a non-linear behavior is expressed, similar to when the concentration is real high. In addition, due to the very low concentration of copper in the fertilizers, when the LIBS predicted value is off by a fraction in comparison to the FAAS values, it raises the average error value significantly. This is not the case with other elements, because the concentration values are higher and some change doesn't necessarily raise the average error value significantly. 
Figure 36 - Cross-Validation error analysis for $\mathrm{Cu}$ between FAAS and LIBS Predicted Value

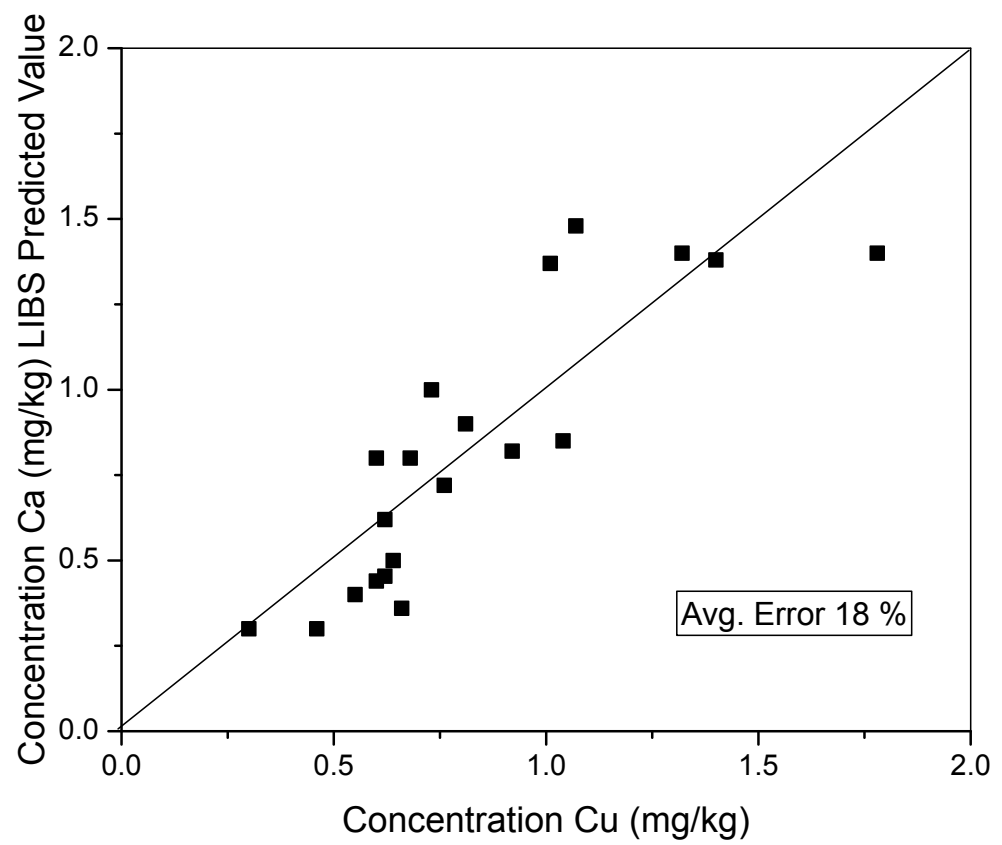

Source: Self-Authorship

Table 6 - Cross-Validation error analysis for FAAS models

\begin{tabular}{|c|c|}
\hline Elements & $\begin{array}{c}\text { LIBS-FAAS average error } \\
\text { analysis (\%) }\end{array}$ \\
\hline Potassium $(\mathrm{K} \mathrm{I})$ & 12 \\
\hline Calcium $(\mathrm{Ca} \mathrm{I})$ & 21 \\
\hline Manganese $(\mathrm{Mn} \mathrm{II})$ & 13 \\
\hline Magnesium $(\mathrm{Mg} \mathrm{I})$ & 8 \\
\hline Copper $(\mathrm{Cu} \mathrm{I})$ & 18 \\
\hline
\end{tabular}

Source: Self-Authorship 


\section{CONCLUSION}

The plasma temperature was calculated using 3 samples pertaining to 3 different types of matrices and the results were similar across the 3 samples. The consistency in the calculation of the plasma temperature was due to the normalization procedure applied, since it corrects for plasma fluctuation, which is known to influence the emission (intensity) signal, which is an important parameter of the calculation. In theory, since the fertilizers were of different matrices, the plasma should have been influenced, thus producing not so precise temperatures amongst the samples. Measurements however, were precise and it was due to the correction method applied.

The SAM technique was used to help eliminate spectral outliers, so that the best representative line of each element could be selected. Following the application of the SAM technique, the normalization procedure was applied and proved to be adequate in correcting for the differences in the matrix effects of fertilizers, thus allowing for the building of calibration models. The resulting correlation of the elements between LIBS and the reference technique proved to be adequate.

Furthermore, the LIBS technique was applied successfully to the quantification of elements $\mathrm{K}, \mathrm{Mn}, \mathrm{Mg}, \mathrm{Ca}$, and $\mathrm{Cu}$ present in fertilizers made up of different physical matrices, with organomineral fertilizers never having been evaluated before using a commercial LIBS system. The LIBS instrument proved to be precise in its measurements and this was shown through the 150-day analysis, where the error was within $10 \%$, thus producing results that can be reproducible, which is an important characteristic for any analytical instrument to have.

When applying the cross-validation error analysis, results were adequate when samples below the LOD were removed. The acceptable error analysis of the LIBS system can be lauded to its potential to be accurate, which is an important characteristic to have in addition to precision. The accuracy and precision of an instrument is what make it credible, thus we are confident that LIBS can perform the quantification of some elements in fertilizers of different matrices with consistency and an acceptable error, as long as they are above the LOD. 


\section{FUTURE WORK}

Suggestions for future work would be in the evaluation of toxic elements such as $\mathrm{Hg}$, $\mathrm{Pb}$, and $\mathrm{Cd}$. The reason it is difficult to analyze these elements is because often, either further preparation is needed in order for the reference techniques to quantify them or their presence is too small in fertilizers and their concentration cannot be reliably determined. The LIBS instrument is also not sensitive enough to produce adequate results for quantification. To analyze these elements using LIBS, further correction of the peak would need to be done, in order to extract reliable data from the peak and build calibration curves. Also, the analysis of Nitrogen $(\mathrm{N})$ is another element that is of great interest. Nitrogen makes part of the three essential nutrients in fertilizer, also known as "NPK", which stands for Nitrogen, Phosphorus, and Potassium. The challenge that $(\mathrm{N})$ presents, is its natural presence in the atmosphere, and due to the abilities of LIBS to analyze solids, liquids, or gases, the $(\mathrm{N})$ in the atmosphere interferes with the $(\mathrm{N})$ present in the fertilizer. A correction specific for the analysis of element $(\mathrm{N})$ would need to be created, to make this analysis possible. 


\section{REFERENCES}

1 Associação Nacional para Difusão de Adubos. Estatistíca de fertilizantes. São Paulo, Brazil, 2016. Available: $<$ http://anda.org.br/index.php?mpg=03.00.00 $>$ Accessed on: 25 Oct. 2016.

2 THE WORLD BANK. Food and agriculture organization. Washington D.C., USA, 2016. Available: < www.worldbank.org/en/about> Accessed on: 25 Oct. 2016.

3 UNITED STATES CENSUS BUREAU. World population. Washington D.C., USA, 2016. Available: <https://www.census.gov/popclock/world> Accessed on: 25/10/2016

4 Agroservices International. Environmental problems with fertilizers. Florida, USA, 2008. Available: $\quad<$ http://www.agroservicesinternational.com/Environment/Problems.html $>$ Accessed on: 25/10/2016

5 VANEECKHAUTE, C.; MEERS, E.; MICHELS, E.; BUYSSE, J.; TACK, F.M.G. Ecological and economic benefits of the application of bio-based mineral fertilizers in modern agriculture. Biomass and Bioenergy, v. 49, p. 239-248, 2012.

6 SINGH, B.; SEKHON, G.S. Nitrate pollution of groundwater from farm use of nitrogen fertilizers. Agriculture and Environment, v. 4, n. 3, p. 207-225, 1979.

7 SINGH, B.; SINGH, Y.; SEKHON, G.S. Fertilizer-N use efficiency and nitrate pollution of groundwater in developing countries. Journal of Contaminant Hydrology, v. 20, n. 3-4, p. 167-184, 1995.

8 PENA-HARO, S.; LLOPIS-ALBERT, C.; PULIDO-VELAZQUEZ, M.; PULIDOVELAZQUEZ, D. Fertilizer standards for controlling groundwater nitrate pollution from agriculture: El Salobral-Los Llanos case study, Spain. Journal of Hydrology. v. 392, n. 3-4, p. 174-187.

9 VOLOKH, A.A.; GORBUNOV, A.V.; GUNDORINA, S.F.; REVICH, B.A.; FRONTASYEVE, M.V.; SEN PAL, C. Phosphorus fertilizer production as a source of rareelements pollution of the environment. Science of The Total Environment. v. 95, p. 141$148,1990$.

10 YAO, S.; LU, J.; LI, J.; CHEN, K.; LI, J.; Dong, M. Multi-elemental analysis of fertilizer using laser-induced breakdown spectroscopy coupled with partial least squares regression. Journal of Analytical Atomic Spectrometry. v. 25, p. 1733-1738, 2010.

11 GONDAL, M. A. Elemental analysis of soils by laser breakdown spectroscopy. In: MUSAZZI, S.; PERINI, U. (Ed.). Laser-Induced Breakdown Spectroscopy-Theory and Applications. New York: Springer-Heidelberg, 2014. v. 182, p. 293-308.

12 APPLIED SPECTRA. What is LIBS?. Fremont, USA, 2004. Available: < http://appliedspectra.com/technology/libs.html> Accessed on: 25 Oct. 2016. 
13 SENESI, G. S.; SENESI, N. Laser-induced breakdown spectroscopy (LIBS) to measure quantitatively soil carbon with emphasis on soil organic carbon. A review. Analytica Chimica Acta. v. 938, p. 7-17, 2016.

14 UNNIKRISHNAN, V. K.; NAYAK, R.; AITHAL, K.; KARTHA, V. B.; SANTHOSH, C.; GUPTA, G. P.; SURI, B. M. Analysis of trace elements in complex matrices (soil) by Laser Induced Breakdown Spectroscopy (LIBS). Analytical Methods. v. 5, n. 5, p. 12941300, 2013.

15 KIM, G.; KWAK, J.; KIM, K. R.; LEE, H.; KIM, K. W.; YANG, H.; PARK, K. Rapid detection of soils contaminated with heavy metals and oils by laser induced breakdown spectroscopy (LIBS). Journal of Hazardous Materials. v. 263, p. 754-760, 2013.

16 TREVIZIAN, L. C.; SANTO JR, D.; SAMAD, R. E.; VIEIRA Jr, N. D; NUNES, L. C.; RUFINI, I. A.; KRUG, F. J. Evaluation of laser induced breakdown spectroscopy for the determination of micronutrients in plant materials. Spectrochimica Acta Part B. v. 64, p. 369-377, 2009.

17 NUNES, L. C.; BRAGA, J. W. B.; TREVIZIAN, L. C.; SOUZA, P. F.; CARVALHO, G. G. A.; JUNIOR, D. S.; POPPI, R. J.; KRUG, F. J. Optimization and validation of a LIBS method for the determination of macro and micronutrients in sugar cane leaves. Journal of Analytical Atomic Spectrometry. v. 25, p. 1453-1460, 2010.

18 AGUilerA, J.A.; ARAGON, C.; MADURGA, V.; MANRIQUE, J. Study of matrix effects in laser induced breakdown spectroscopy on metallic samples using plasma characterization by emission spectroscopy. Spectrochimica Acta Part B: Atomic Spectroscopy. v. 64, p. 993-998, 2009.

19 NUNES, L. C.; CARVALHO, G. G. A.; SANTOS, D.; KRUG, F. J. Determination of Cd, $\mathrm{Cr}$, and $\mathrm{Pb}$ in phosphate fertilizer by laser-induced breakdown spectroscopy. Spectrochimica Acta Part B: Atomic Spectroscopy. v. 97, p. 42-48, 2014.

20 CHEN, S. H.; LU, J.; LI, J.; LUO, J. The plasma characteristic of different kinds of coal particles flow. Journal of Optoelectronics Laser. v. 24, n. 3, p. 596-601, 2013.

21 MARANGONI, B. S.; SILVA, K. S. G.; NICOLODELLI, G.; SENESI, G. S.; CABRAL, J. S.; VILLAS-BOAS, P. R.; SILVA, S. S.; TEIXEIRA, P. C.; NOGUEIRA, A. R. A.; BENITES, V. M.; MILORI, D. M. B. P. Phosphorus quantification in fertilizers using laser induced breakdown spectroscopy (LIBS): a methodology of analysis to correct physical matrix effects. Analytical Methods. v. 8, p.78-82, 2016.

22 TREVIZIAN, L. C.; SANTOS Jr, D.; SAMAD, R. E.; VIEIRA Jr, N. D.; NOMURA, C. S.; NUNES L. C.; RUFINI, I. A.; KRUG, F. J. Evaluation of laser induced breakdown spectroscopy for the determination of macronutrients in plant materials. Spectrochimica Acta Part B: Atomic Spectroscopy. v. 63, p. 1151-1158, 2008. 
23 KAISER, J.; MALINA, R.; NOVOTNY, J.; PROCHAZKA, D.; NOVOTNY, K. ; KRAJCAROVA, L.; GALIOVA, M.; HOLA, M. Utilization of the Laser-Induced Breakdown Spectroscopy (LIBS) for spectrochemical analysis of plant samples with high spatial resolution. In: Computational Optical Sensing and Imaging. Washington D.C.: Optical Society of America, 2009. Paper JTuC12

24 GIBSON, B.; CARTER, S.; FISHER, A. S.; LANCASTER, S.; MARSHALL; WHITESIDE, I. Atomic spectrometry update. Review of advances in the analysis of metals, chemicals and functional materials. Journal of Analytical Atomic Spectrometry. v. 29, p. 1969-2021, 2014.

25 HAHN, D. W.; OMENETTO, N. Laser-Induced Breakdown Spectroscopy (LIBS), Part I: Review of basic diagnostics and plasma-particle interactions: still-challenging issues within the analytical plasma community. Journal of Applied Spectroscopy. v. 64, p. 335-366, 2010 .

26 SEGINI, A.; XAVIER, A. A. P.; OTAVIANI-JUNIOR, P. L.; FERREIRA, E. C.; WATANABE, A. M.; SEPERANCA, M. A.; NICOLODELLI, G.; VILLAS-BOAS, P. R.; OLIVEIRA, P. P. A.; MILORI, D. M. B. P. Physical and chemical matrix effects in soil carbon quantification using laser-induced breakdown spectroscopy. Analytical Chemistry. v. 5, n. 11, p. 722-729, 2014.

27 MUKHONO, P. M.; ANGEYO, K. H.; KAMADJEU, A. D.; KADUKI, K. A. Laser induced breakdown spectroscopy and characterization of environmental matrices utilizing multivariate chemometrics. Spectrochimica Acta Part B: Atomic Spectroscopy v. 87, p. 81-85, 2013.

28 ZHANG, S.; ZHANG, B.; HANG, W.; HUANG, B. Chemometrics and theoretical approaches for evaluation of matrix effects in laser ablation and ionization of metal samples. Spectrochimica Acta Part B: Atomic Spectroscopy. v. 107, p. 17-24, 2015.

29 BOUCHER, T. F.; OZANNE, M. V.; CARMOSINO, M. L.; DYAR, M. D.; MAHADEVAN, S.; BREVES, E. A.; LEPORE, K. H.; CLEGG, S. M. A study of machine learning regression for major elemental analysis of rocks using laser-induced breakdown spectroscopy. Spectrochimica Acta Part B: Atomic Spectroscopy. v. 107, p. 1-10, 2015.

30 AHMED, R.; BAIG, M. A. A comparative study of single and double pulse laser induced breakdown spectroscopy. Journal of Applied Physics. v. 106, n. 3, 2009.

31 AHMED, R.; BAIG, M. A. On the Optimization for enhanced dual-pulse laser-induced breakdown spectroscopy. IEET Transactions on Plasma Science. v. 38, n. 8, p. 2052-2055, 2010.

32 SPECTROSCOPYONLINE. LIBS and the MARS Curiosity Rover. Pasadena, USA, 2016. Available: <http://www.spectroscopyonline.com/libs-and-mars-curiosity-rover> Accessed on: 25 Oct. 2016.

33 SNYDER, M. L.; SCAFFIDI, J.; ANGEL, M.; MICHEL, A. P. M.; CHAVE, A. D. Sequential-pulse laser-induced breakdown spectroscopy of high-pressure bulk aqueous solutions. Journal of Applied Spectroscopy. v. 61, n. 2, p. 171-176, 2007 
34 LAZIC, V.; COLAO, F.; FANTONI, R.; SPIZZICCHINO, V. Laser-induced breakdown spectroscopy in water: Improvement of the detection thresholds by signal processing. Spectrochimica Acta Part B: Atomic Spectroscopy. v. 60, n. 7-8. p. 1002-1013, 2005.

35 NICOLODELli, G.; SENESI, G. S.; PERAZZOLI, I. L. O.; MARANGONI, B. P.; BENITES, V. M.; MILORI, D. M. B. P. Double pulse laser induced breakdown spectroscopy: A potential tool for the analysis of contaminants and macro/micronutrients in organic mineral fertilizers. Science of The Total Environment. v. 565, p. 1116-1123, 2016.

36 MATSUMOTO, A.; TAMURA, A.; KODA, R.; FUKAMI, K.; OGATA, Y. H.; NISHI, N.; THORNTON, B.; SAKKA, T. On-site quantitative elemental analysis of metal ions in aqueous solutions by underwater laser-induced breakdown spectroscopy combined with electrodeposition under controlled potential. Analytical Chemistry. v. 87, n. 3, p. 1655-1661, 2015 .

37 MELIKECHI, N.; MEZZACAPPA, A.; COUSIN, A.; LANZA, N. L.; LASUE, J.; CLEGG, S. M.; BERGER, G.; WIENS, R.C.; MAURICE, S.; TOKAR, R. L.; BENDER, S.; FORNI, O.; BREVES E.A.; DYAR, M.D.; FRYDENVANG, J.; DELAP, D.; GASNAULT, O.; NEWSOM, H.; OLLILA, A.M.; LEWIN, E.; CLARK, B.C.; EHLMANN, B.L.; BLANEY, D. The MSL Science Team. Correcting for variable laser-target distances of laserinduced breakdown spectroscopy measurements with ChemCam using emission lines of Martian

38 JOYCE, R. F.; WOLTZ, L. A.; HOOPER, C. F. Asymmetry of stark-broadened lyman lines from laser-produced plasmas. Physical Review A. v. 35, n. 5, p. 2228, 1987.

39 RASHMI, S.; ADDAMANI, S.; VENKAT,; RAVIKIRAN, S. Spectral angle mapper algorithm for remote sensing image classification. Innovative Science, Engineering \& Technology. v. 1, n.4, p. 201-205, 2014.

40 NATIONAL INSTITUTE of STANDARDS and TECHNOLOGY. NIST Atomic Spectra Database Lines Form. Maryland, USA, 2016. Available: $<$ http://physics.nist.gov/PhysRefData/ASD/lines_form.html> Accessed on: 25 Oct. 2016.

41 RAI, V. N.; THAKUR, S. N. Theoretical models for plasma. In: SINGH, J. P.; THAKUR, S. N. (Ed.). Laser-induced breakdown spectroscopy. Oxford: Elsevier, 2007. p. 88-94.

42 NAJARIAN, M. L.; CHINNI, R. C. Temperature and electron density determination on laser-induced breakdown spectroscopy (LIBS) plasmas: A physical chemistry experiment. Journal of Chemical Education. v. 90, n. 2, p. 244-247, 2012.

43 GRIEM, H. R. Spectral Line Broadening by Plasmas: Griem's appendix III a. New York: Academic Press, 1974. p. 315-316.

44 CURRIE, L. A. Limits of qualitative detection and quantitative determination. Application to radiochemistry. Analytical Chemistry. v. 40, n.3, p. 586-593. 